\title{
European Consensus Guidelines on the Management of Respiratory Distress Syndrome - 2019 Update
}

\begin{abstract}
David G. Sweet $^{\mathrm{a}}$ Virgilio Carniellib ${ }^{\mathrm{b}}$ Gorm Greisen ${ }^{c}$ Mikko Hallman $^{\mathrm{d}}$
Eren Ozek ${ }^{\mathrm{e}}$ Arjan te Pas $^{\mathrm{f}}$ Richard Plavkag Charles C. Roehr ${ }^{\mathrm{h}}$ Ola D. Saugstad ${ }^{\mathrm{i}}$ Umberto Simeoni ${ }^{j}$ Christian P. Speerk Maximo Ventol Gerhard H.A. Visserm Henry L. Halliday ${ }^{n}$

a Regional Neonatal Unit, Royal Maternity Hospital, Belfast, UK; ${ }^{b}$ Department of Neonatology, Polytechnic University of Marche, and Azienda Ospedaliero-Universitaria Ospedali Riuniti Ancona, Ancona, Italy; ' ${ }^{\text {Department of }}$ Neonatology, Rigshospitalet and University of Copenhagen, Copenhagen, Denmark; ${ }^{d}$ Department of Pediatrics and Adolescence, Oulu University Hospital, and PEDEGO Research Unit, Medical Research Center, University of Oulu, Oulu, Finland; e Department of Pediatrics, Marmara University Medical Faculty, Istanbul, Turkey; ${ }^{\mathrm{f} L e i d e n}$ University Medical Centre, Leiden, The Netherlands; ${ }^{9}$ Division of Neonatology, Department of Obstetrics and Gynecology, General Faculty Hospital and 1st Faculty of Medicine, Charles University, Prague, Czech Republic; ${ }^{\text {h}}$ Department of Paediatrics, University of Oxford, Medical Sciences Division, Newborn Services, John Radcliffe Hospitals, Oxford, UK; ' Department of Pediatric Research, Oslo University Hospital Rikshospitalet, University of Oslo, Oslo,

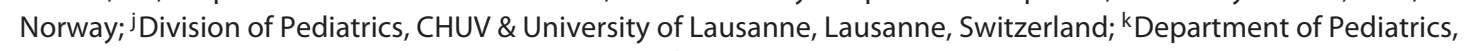
University Children's Hospital, Würzburg, Germany; 'Department of Pediatrics and Neonatal Research Unit, Health

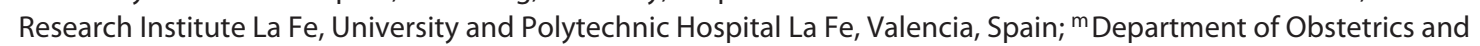
Gynecology, University Medical Centre, Utrecht, The Netherlands; ${ }^{n}$ Department of Child Health, Queen's University Belfast and Royal Maternity Hospital, Belfast, UK
\end{abstract}

\section{Keywords}

Antenatal steroids - Continuous positive airway pressure Evidence-based practice $\cdot$ Hyaline membrane disease · Mechanical ventilation · Nutrition · Oxygen supplementation · Patent ductus arteriosus · Preterm infant · Respiratory distress syndrome · Surfactant therapy · Thermoregulation

These updated Guidelines contain new evidence from recent Cochrane reviews and the medical literature since 2016. Strength of evidence supporting recommendations has been evaluated using the GRADE system. The prenatal care section has been updated by Prof. Gerard H.A. Visser. There are also new recommendations covering less invasive surfactant administration. This guideline has been endorsed by the European Society for Paediatric Research (ESPR).

\section{KARGER}

E-Mail karger@karger.com www.karger.com/neo

\section{(C) 2019 The Author(s)}

Published by S. Karger AG, Basel

Karger
Open access

This article is licensed under the Creative Commons AttributionNonCommercial-NoDerivatives 4.0 International License (CC BYNC-ND) (http://www.karger.com/Services/OpenAccessLicense). Usage and distribution for commercial purposes as well as any distribution of modified material requires written permission.

\begin{abstract}
As management of respiratory distress syndrome (RDS) advances, clinicians must continually revise their current practice. We report the fourth update of "European Guidelines for the Management of RDS" by a European panel of experienced neonatologists and an expert perinatal obstetrician based on available literature up to the end of 2018. Optimising outcome for babies with RDS includes prediction of risk of preterm delivery, need for appropriate maternal transfer to a perinatal centre and timely use of antenatal steroids. Delivery room management has become more evidencebased, and protocols for lung protection including initiation of CPAP and titration of oxygen should be implemented immediately after birth. Surfactant replacement therapy is a crucial part of management of RDS, and newer protocols for
\end{abstract}

Dr. David G. Sweet, MD, FRCPCH

Regional Neonatal Unit, Royal Maternity Hospital

274 Grosvenor Road

Belfast BT12 6BB (UK)

E-Mail david.sweet@ belfasttrust.hscni.net 
its use recommend early administration and avoidance of mechanical ventilation. Methods of maintaining babies on non-invasive respiratory support have been further developed and may cause less distress and reduce chronic lung disease. As technology for delivering mechanical ventilation improves, the risk of causing lung injury should decrease, although minimising time spent on mechanical ventilation using caffeine and, if necessary, postnatal steroids are also important considerations. Protocols for optimising general care of infants with RDS are also essential with good temperature control, careful fluid and nutritional management, maintenance of perfusion and judicious use of antibiotics all being important determinants of best outcome.

C 2019 The Author(s)

Published by S. Karger AG, Basel

\section{Introduction}

Respiratory distress syndrome (RDS) remains a significant problem for preterm babies, although management has evolved gradually over the years resulting in improved survival for the smallest infants but with unacceptable rates of bronchopulmonary dysplasia (BPD) at least in part due to reduced use of postnatal steroids [1]. Since 2006, a panel of neonatologists from many European countries have met 3-yearly to review the most recent literature and develop consensus recommendations for optimal management of preterm babies with or at risk of RDS in order to achieve the best outcomes for neonates in Europe. The "European Consensus Guidelines for the Management of RDS" were first published in 2007 and have been updated in 2010, 2013 and 2016 and are endorsed by the European Society for Paediatric Research [2-5]. The Guidelines have been translated into several languages including Chinese [6], and although primarily intended for use in Europe, they contain recommendations that potentially could be used anywhere provided clinicians have access to all the resources and experience needed to provide modern neonatal intensive care.

Although primarily a disorder of surfactant deficiency resulting in pulmonary insufficiency from soon after birth, the classical clinical description of RDS has changed as treatments have evolved over the years. Radiographic appearances of "ground glass with air bronchograms" are rarely seen today due to early surfactant therapy and early continuous positive airway pressure (CPAP). Definitions based on blood gas analyses are also increasingly redundant as clinicians have moved towards a more pragmatic approach of giving surfactant therapy based on clinical assessment of work of breathing and inspired ox-

Consensus Guidelines on the

Management of RDS ygen requirement very early in the clinical course. Knowing how many babies have genuine RDS is therefore difficult. Of the 8,156 babies from Europe for whom data were submitted to the Vermont Oxford Network during 2017 , RDS was coded for about $80 \%$ of babies born at 28 weeks' gestation increasing to $90 \%$ at 24 weeks' gestation [7]. Surfactant was given to $55 \%$ of very low birth weight (VLBW) infants, $27 \%$ in the delivery room and $29 \%$ beyond $2 \mathrm{~h}$ of age, suggesting that prophylactic surfactant is still being used. Chronic lung disease (or BPD) was coded for $18 \%$ of VLBW infants in Europe.

The aim of management of RDS is to provide interventions to maximise survival whilst minimising potential adverse effects including BPD. Many strategies and therapies for prevention and treatment of RDS are being tested in clinical trials, and many new studies have been incorporated into updated systematic reviews. These Guidelines update the previous four guidelines after critical examination of the most recent evidence available in late 2018. We have again used a format of summarising management strategies followed by evidence-based recommendations according to the GRADE system to reflect the authors' views on the strength of evidence supporting each of the recommendations [8]. Quality of evidence and strength of recommendations are summarised in Table 1. Summary of recommendations is shown in Appendix 1.

\section{Prenatal Care}

Lack of antenatal care increases risk of death or severe morbidity [9]. There are no generally effective means to prevent spontaneous or elective preterm births. However, in pregnant women at risk of spontaneous preterm birth due either to previous preterm birth or where a shortened cervix has been identified, use of progesterone is associated with reduced preterm delivery rates and reduced neonatal mortality $[10,11]$. Routine cervical length measurements may be advised in populations at risk of preterm birth but not in populations with an overall low risk and/or very low incidence of short cervix [12]. Cervical cerclage may also reduce preterm birth in high-risk singleton pregnancies [13]. The present challenge is to identify high-risk pregnancies early and aim for effective prevention of preterm birth.

Interventions to improve outcome and prevent RDS begin before birth. There is often warning of impending preterm delivery, and in these cases a need to consider interventions to prolong gestation or reduce risk of an adverse outcome by "preparing" the fetus. Cervical length 
Table 1. Representations of quality of evidence and strength of recommendations

$\begin{array}{lc}\text { Quality of evidence } & \\ \text { High quality } & \text { A } \\ \text { Moderate quality } & \text { B } \\ \text { Low quality } & \text { C } \\ \text { Very low quality } & \text { D } \\ \text { Strength of recommendation } & \\ \quad \text { Strong recommendation for using intervention } & 1 \\ \text { Weak recommendation for using intervention } & 2\end{array}$

measurement possibly in combination with a biomarker may determine which women are actually at risk of delivery within 7 days and allow more judicious use of antenatal treatments [14]. Extremely preterm babies should, if possible, be transported in utero to tertiary centres where appropriate skills are available; best outcomes are achieved for babies born in centres with a high throughput of VLBW babies [15]. In cases of prenatal pre-labour rupture of membranes (PPROM), antibiotics can delay preterm delivery and reduce neonatal morbidity, although co-amoxiclav should be avoided because of its association with increased risk of necrotising enterocolitis (NEC) [16]. Magnesium sulphate $\left(\mathrm{MgSO}_{4}\right)$ given to women with imminent preterm delivery reduces cerebral palsy at 2 years of age by about 30\% [17], although longer-term benefits are less clear [18]. Tocolytic drugs can be used in the short-term to delay birth, permit safe transfer to a perinatal centre and allow prenatal corticosteroids time to take effect, although tocolytics have no direct beneficial effect on the fetus [19]. Given their limited value, only drugs that are safe for the mother should be considered, that is oxytocin antagonists or Ca-channel blockers [20].

A single course of prenatal corticosteroids given to mothers with anticipated preterm delivery improves survival, reduces RDS, NEC and intraventricular haemorrhage and does not appear to be associated with any significant maternal or short-term fetal adverse effects [21]. Prenatal corticosteroid therapy is recommended in all pregnancies with threatened preterm birth before 34 weeks' gestation where active care of the newborn is anticipated. Although there are limited RCT data in babies at $<25$ weeks' gestation, observational studies suggest that antenatal corticosteroids, together with other active management practices, reduce mortality at gestations as low as 22 weeks [22]. In pregnancies between 34 and 36 weeks' gestation, prenatal steroids also reduce risk of short-term respiratory morbidity but not mortality, and there is increased risk of neonatal hypoglycaemia [23]. Long-term follow-up data are broadly reassuring, albeit sketchy [24], and given the potential for long-term side-effects, steroids are not currently recommended for women in spontaneous preterm labour after 34 weeks [25]. When given before elective Caesarean section (CS) up to 39 weeks, they reduce risk of admission to NICU, although the number needed to treat is $>20$ and follow-up data on term babies exposed to antenatal steroids are lacking [26]. The optimal treatment to delivery interval is more than $24 \mathrm{~h}$ and less than 7 days after the start of steroid treatment; beyond 14 days, benefits are diminished. Beneficial effects of the first dose of antenatal steroid start within a few hours, so advanced dilatation should not be a reason to refrain from therapy and the same may hold for $\mathrm{MgSO}_{4}$ [27]. There is still debate as to whether steroids should be repeated 1 or 2 weeks after the first course for women with threatened preterm labour. A repeat course reduces the risk of respiratory support. However, it decreases fetal growth, and repeat doses do not reduce mortality or other serious health outcomes. No effect on neurosensory disability in follow-up has been observed, but data on potential longerterm adverse effects are lacking $[28,29]$. WHO recommends that a single repeat course of steroids may be considered if preterm birth does not occur within 7 days after the initial course and there is a high risk of preterm birth in the next 7 days [30]. It is unlikely that repeat courses given after 32 weeks' gestation improve outcome [31].

Steroids are potent drugs with many side effects, but when given appropriately they improve outcome. If not, then side effects, such as impaired fetal and placental growth, apoptosis in the brain and increased infection, may prevail. Use of steroids should be reduced by adequate preterm birth risk assessment and avoidance of unnecessary early elective CS. In some cases when an early CS is needed, establishment of fetal lung maturity may be better than giving steroids to all women [32]. There is little evidence that delivering preterm infants by CS rather than allowing vaginal delivery improves outcome.

\section{Recommendations}

1 Mothers at high risk of preterm birth $<28-30$ weeks' gestation should be transferred to perinatal centres with experience in management of RDS (C1).

2 Clinicians should offer a single course of prenatal corticosteroids to all women at risk of preterm delivery from when pregnancy is considered potentially viable until 34 weeks' gestation ideally at least $24 \mathrm{~h}$ before birth (A1).

3 A single repeat course of steroids may be given in threatened preterm birth before 32 weeks' gestation if the first course was administered at least 1-2 weeks earlier (A2).

$4 \mathrm{MgSO}_{4}$ should be administered to women in imminent labour before 32 weeks' gestation (A2). 
5 In women with symptoms of preterm labour, cervical length and fibronectin measurements should be considered to prevent unnecessary use of tocolytic drugs and/or antenatal steroids (B2).

6 Clinicians should consider short-term use of tocolytic drugs in very preterm pregnancies to allow completion of a course of corticosteroids and/or in utero transfer to a perinatal centre (B1).

\section{Delivery Room Stabilisation}

European Resuscitation Guidelines should be used to deal with asphyxiated babies with hypoxia who need urgent airway opening manoeuvres and lung inflation to restore cardiac output [33]. Preterm babies with RDS will usually try to breathe during transition at birth [34] although they may subsequently struggle to maintain adequate alveolar aeration. "Supporting transition" rather than "resuscitation" is therefore in most cases the preferred term in RDS management, and infants should be allowed to gently transition whilst being exposed to a minimum number of interventions that may cause harm [35]. Birth is defined when the fetus is completely expelled from the uterus, and this is when all timing should start.

Timing of umbilical cord clamping is an important first step. Clamping the cord before initiation of respiration results in an acute transient reduction in left atrial filling leading to an abrupt drop in left ventricular output. Delayed "physiological" clamping after lung aeration results in much smoother transition and less bradycardia in animal models [36]. The Australian Placental Transfusion Study randomised 1,600 babies less than 30 weeks' gestation to immediate (within $10 \mathrm{~s}$ ) or delayed clamping (after 60 s or more) [37]. However, even such a large study was insufficiently powered to determine a difference in the primary outcome of death or major morbidity. Combining these data in a meta-analysis with other trials shows a significant reduction in in-hospital mortality for preterm infants in whom cord clamping was delayed [38]. Specialist resuscitation equipment designed to maintain body temperature makes it feasible to provide advanced resuscitation with the umbilical cord intact [39]. Umbilical cord milking may be an alternative to delayed cord clamping in emergency situations [40]. Two randomised trials including 255 babies $<33$ weeks' gestation offered broad reassurance that short-term outcomes are broadly equivalent [41], and one follow-up study suggested better cognitive and language scores in those randomised to cord milking [42]. However, animal studies show that cord milking causes considerable haemodynamic distur-

Consensus Guidelines on the Management of RDS bance, and a recent clinical trial has shown quadrupling of the incidence of severe intraventricular haemorrhage with cord milking compared to delayed cord clamping in preterm infants calling into question the safety of this procedure [43]. After birth, the baby should be placed in a clear polythene bag and under a radiant warmer to maintain body temperature (see below).

Stimulation of the infant during stabilisation helps with establishing regular respirations [44]. Spontaneously breathing babies should be started on CPAP rather than intubated in the delivery room to reduce risk of BPD [45]. Routine suctioning of the airway before starting CPAP is not beneficial [46]. The ideal level of CPAP is unknown, but most studies have used levels of at least $6 \mathrm{~cm} \mathrm{H}_{2} \mathrm{O}$ with some as high as $9 \mathrm{~cm} \mathrm{H}_{2} \mathrm{O}$. Using higher pressures up to $20-25 \mathrm{~cm} \mathrm{H}_{2} \mathrm{O}$ for a period of around 10-15 s at initiation of respiration (sustained inflation or SI) has been studied as a way of avoiding intubation; however, clinical trials have been disappointing, with no apparent value of SI [47]. The Sustained Inflation of Infants Lung (SAIL) trial was suspended early because of an excess of early deaths in infants receiving the intervention [48], and until further analysis of available data, SI should only be used in clinical trials. To provide measurable CPAP from birth, the Tpiece device is a better choice than a self-inflating anaesthetic bag [49], and the initial interface can either be a face mask or a short nasal prong [50]. Provision of CPAP alone is ideal, and routine use of positive pressure breaths should be discouraged [51], although gentle positive pressure ventilation may be required for babies who remain apnoeic or bradycardic. Heating and humidification of gases used for stabilisation is ideal in terms of preventing heat loss [52]. Immediate wrapping in a polythene bag under a radiant warmer also reduces heat loss [53], and increasing the environmental temperature in the delivery room to around $26^{\circ} \mathrm{C}$ is also recommended for babies less than 28 weeks [33]. Heated, humidified oxygen delivered by high-flow nasal cannula (HFNC) has also been studied as a primary mode of respiratory support but was inferior to CPAP in terms of failure, with babies randomised to HFNC often needing rescue with CPAP to prevent intubation [54].

Heart rate assessment is important in determining infant well-being during transition. Heart rate $<100 / \mathrm{min}$ for $>2 \mathrm{~min}$ in the first $5 \mathrm{~min}$ after birth is associated with 4.5fold increase in mortality [55]. Monitoring heart rate can be done by stethoscope, electrocardiography, pulse oximetry or photoplethysmography. Pulse oximetry signals are often delayed for up to a minute. Auscultation with a stethoscope may not be as accurate as ECG in determining heart rate during transition; however, for most units at present ECG 
is not universally available [56]. Provided heart rate is satisfactory, the aim is, where possible, to mimic normal transitional saturations measured at the right wrist by pulse oximetry with saturations gradually rising from about 60 $90 \%$ over the first $10 \mathrm{~min}$ after birth. Blended air/oxygen should therefore be available. For term babies requiring resuscitation, there is reduced mortality when using fraction of inspired oxygen $\left(\mathrm{FiO}_{2}\right) 0.21$ rather than 1.0 [57]. There is evidence of increased oxidative stress when starting preterm infants in $100 \%$ oxygen; however, there is still uncertainty about the longer-term effects of high or low oxygen exposure at birth in preterm infants [58]. Observational studies have raised concerns about starting extremely preterm infants in air because of poorer recovery from bradycardia and increased mortality in the smallest babies [59]. Moreover, the combination of bradycardia $(<100 / \mathrm{min})$ and lower $\mathrm{SpO}_{2}(<80 \%)$ in the first $5 \mathrm{~min}$ is associated with death or intracranial haemorrhage [60]. Further trials are underway to resolve this issue. Presently, it is known that when titrating oxygen, most infants end up in about 30$40 \%$ oxygen by $10 \mathrm{~min}$, so we believe it is reasonable to start preterm infants $<28$ weeks in about $30 \%$ oxygen until more evidence is available [61]. For those between 28 and 31 weeks' gestation, 21-30\% oxygen is recommended [62].

Only a minority of babies should require intubation for stabilisation. If intubation is required, the correct placement of the endotracheal tube can be quickly verified clinically by auscultation and using a colorimetric $\mathrm{CO}_{2}$ detection device before administering surfactant which in most circumstances can be done prior to radiographic confirmation of RDS.

\section{Recommendations}

1 Delay clamping the umbilical cord for at least $60 \mathrm{~s}$ to promote placento-fetal transfusion (A1).

2 In spontaneously breathing babies, stabilise with CPAP of at least $6 \mathrm{~cm} \mathrm{H}_{2} \mathrm{O}$ via mask or nasal prongs (B1). Do not use SI as there is no long-term benefit (B1). Gentle positive pressure lung inflations with $20-25 \mathrm{~cm} \mathrm{H}_{2} \mathrm{O}$ peak inspiratory pressure (PIP) should be used for persistently apnoeic or bradycardic infants.

3 Oxygen for resuscitation should be controlled using a blender. Use an initial $\mathrm{FiO}_{2}$ of 0.30 for babies $<28$ weeks' gestation and $0.21-0.30$ for those 28-31 weeks, 0.21 for 32 weeks' gestation and above. $\mathrm{FiO}_{2}$ adjustments up or down should be guided by pulse oximetry (B2).

4 For infants $<32$ weeks' gestation, $\mathrm{SpO}_{2}$ of $80 \%$ or more (and heart rate $>100 / \mathrm{min}$ ) should be achieved within $5 \mathrm{~min}$ (C2).

5 Intubation should be reserved for babies not responding to positive pressure ventilation via face mask or nasal prongs (A1). Babies who require intubation for stabilisation should be given surfactant (B1).
6 Plastic bags or occlusive wrapping under radiant warmers should be used during stabilisation in the delivery suite for babies $<28$ weeks' gestation to reduce the risk of hypothermia (A1).

\section{Surfactant Therapy}

Surfactant therapy plays an essential role in management of RDS as it reduces pneumothorax and improves survival. However, intratracheal administration requires skill and may cause harm, particularly if uncontrolled positive pressure is applied to the newborn lung. Prior to 2013, prophylactic surfactant was recommended for the smallest babies as it improved survival in clinical trials from the pre-CPAP era [63]. After 2013, with increased use of antenatal steroids and early initiation of CPAP, outcomes are best if surfactant is reserved for infants showing clinical signs of RDS, and for the smallest infants early initiation of CPAP may avoid the harmful effects of intubation and mechanical ventilation (MV) during the transitional phase. The overall aim is to avoid invasive MV if possible whilst endeavouring to give surfactant as early as possible in the course of RDS once it is deemed necessary.

\section{Surfactant Administration Methods}

Surfactant administration requires an experienced practitioner with intubation skills and ability to provide MV if required. Most surfactant clinical trials to date have used tracheal intubation, bolus administration with distribution of surfactant using intermittent positive pressure ventilation, either manually or with a ventilator, followed by a period of weaning from MV as lung compliance improves. The IN-SUR-E technique allows surfactant to be given without ongoing MV and was endorsed previously as it may reduce BPD [64]. In the last decade, new methods for administering surfactant using a fine catheter placed in the trachea under direct or video-laryngoscopy, with the infant spontaneously breathing on CPAP, have been described, thereby avoiding exposure to positive pressure ventilation. Specialised catheters designed for this method, known as less invasive surfactant administration (LISA), are commercially available. Since the 2016 Guideline, there have been further randomised trials and meta-analyses comparing these methods. These suggest that LISA is superior in terms of reducing need for $\mathrm{MV}$ and the combined outcome of death or BPD [65]. However, these meta-analyses include some studies that are open to bias and might not be suitable for inclusion in a more rigorous systematic review. Nevertheless, studies of higher quality, such as those from 
the German Neonatal Network, all show trends for improvement favouring LISA, and it is reasonable to recommend it as the optimal method of surfactant administration for spontaneously breathing babies who are stable on CPAP. Some units also employ strategies of prophylactic LISA for the smallest babies, although this has not yet been tested in randomised controlled trials [66]. One of the advantages of LISA is that the temptation to continue MV following surfactant is removed. This makes the issue of sedation for the procedure more complex. It is considered good practice to avoid discomfort during elective intubation by using a sedative or analgesic such as fentanyl, propofol or midazolam (see later). Using low-dose sedation prior to laryngoscopy for the LISA procedure is technically feasible, will make the baby less uncomfortable but will increase the risk of CPAP failure [67]. At present, there is no clear answer about whether to sedate routinely for LISA, and individual neonatologists must decide for themselves.

Surfactant delivered by nebulisation would be truly non-invasive. With development of vibrating membrane nebulisers, it is possible to atomise surfactant, although only one clinical trial has shown that nebulising surfactant when on CPAP reduces need for MV compared to CPAP alone, and this finding was limited to a subgroup of more mature infants of 32-33 weeks [68]. Further trials of nebulisation are ongoing. Surfactant has also been administered by laryngeal mask airway, and one clinical trial shows that this reduces need for intubation and MV [69]. However, the size of currently available laryngeal masks limits use of the method to relatively mature preterm infants, and routine use for smaller infants at greatest risk of BPD is not recommended [70]. Pharyngeal deposition of surfactant at birth is also currently being tested in clinical trials.

\section{When to Treat with Surfactant?}

If intubation is required as part of stabilisation, then surfactant should be given immediately, as the main purpose of avoiding surfactant prophylaxis is to avoid intubation. Many preterm infants will transition successfully on CPAP. Those with RDS will develop progressively worsening lung disease, clinically presenting as increased work of breathing, sternal recession and increasing oxygen requirements to maintain normal saturations. Spontaneous recovery usually begins after $48-72 \mathrm{~h}$, and some infants with milder disease may manage without surfactant, thereby avoiding the discomfort of laryngoscopy and potential deleterious effects of intubation. Early trials showed that surfactant given earlier in the course of disease works better than later in terms of reducing air leaks [71] and avoiding MV if the IN-SUR-E technique is used

Consensus Guidelines on the

Management of RDS
[72]. This creates a dilemma for neonatologists. At present, severity of RDS can only be determined clinically using a combination of $\mathrm{FiO}_{2}$ to maintain normal saturations, coupled with judgement of work of breathing and degree of aeration of the lungs on chest X-ray, all of which can be influenced by CPAP. Lung ultrasound may be a useful adjunct to clinical decision making in experienced hands, with RDS lungs having a specific appearance that can be differentiated from other common neonatal respiratory disorders [73] and it has potential to reduce X-ray exposure [74]. Rapid bedside tests to accurately determine presence or absence of surfactant in gastric aspirate are currently being tested in clinical trials [75]. The 2013 Guideline suggested that surfactant should be administered when $\mathrm{FiO}_{2}>0.30$ for very immature babies and $>0.40$ for more mature infants based on thresholds used in the early clinical trials. Observational studies have confirmed that $\mathrm{FiO}_{2}$ exceeding 0.30 in the first hours after birth in babies on CPAP is a reasonably good test for predicting subsequent CPAP failure [76]. Therefore it is recommended that the threshold of $\mathrm{FiO}_{2}>0.30$ is used for all babies with a clinical diagnosis of RDS, especially in the early phase of worsening disease.

More than one dose of surfactant may be needed. Clinical trials comparing multiple doses to a single dose showed fewer air leaks, although these were conducted in an era when babies were maintained on MV. Today many infants are maintained on non-invasive ventilation even when surfactant is required. Need for re-dosing can be minimised by using the larger dose of $200 \mathrm{mg} / \mathrm{kg}$ of poractant alfa [77]. Prediction of IN-SUR-E failure using clinical criteria and blood gases could define a population that would be reasonable to maintain on MV for a while after surfactant has been given $[78,79]$.

\section{Surfactant Preparations}

Surfactants currently available in Europe are shown in Table 2. Synthetic surfactants containing both SP-B and SP-C analogues are also currently under evaluation in clinical trials [80]. Animal-derived surfactants have been compared in systematic reviews [77]. Most of the head-to-head trials show that surfactants have similar efficacy when used in similar doses; however, there is a survival advantage when $200 \mathrm{mg} / \mathrm{kg}$ of poractant alfa is compared with $100 \mathrm{mg} / \mathrm{kg}$ of beractant or $100 \mathrm{mg} / \mathrm{kg}$ poractant alfa to treat RDS [77]. Surfactant combined with budesonide significantly reduces BPD [81], although further larger studies with long-term follow-up will be needed before this can be recommended [82]. 
Table 2. Surfactant preparations (animal-derived) licensed in Europe in 2018

\begin{tabular}{llllc}
\hline Generic name & Trade name & Source & Manufacturer & Dose (volume) \\
\hline Beractant & Survant & Bovine & Ross Laboratories (USA) & $100 \mathrm{mg} / \mathrm{kg} / \mathrm{dose}(4 \mathrm{~mL} / \mathrm{kg})$ \\
Bovactant & Alveofact & Bovine & Lyomark (Germany) & $50 \mathrm{mg} / \mathrm{kg} / \mathrm{dose}(1.2 \mathrm{~mL} / \mathrm{kg})$ \\
Poractant alfa & Curosurf & Porcine & Chiesi Farmaceutici (Italy) & $100-200 \mathrm{mg} / \mathrm{kg} / \mathrm{dose}(1.25-2.5 \mathrm{~mL} / \mathrm{kg})$ \\
\hline
\end{tabular}

Recommendations

1 Babies with RDS should be given an animal-derived surfactant preparation (A1).

2 A policy of early rescue surfactant should be standard (A1), but there are occasions when surfactant should be given in the delivery suite, such as when intubation is needed for stabilisation (A1).

3 Babies with RDS should be given rescue surfactant early in the course of the disease. A suggested protocol would be to treat babies who are worsening when $\mathrm{FiO}_{2}>0.30$ on CPAP pressure of at least $6 \mathrm{~cm} \mathrm{H}_{2} \mathrm{O}(\mathbf{B} 2)$.

4 Poractant alfa at an initial dose of $200 \mathrm{mg} / \mathrm{kg}$ is better than $100 \mathrm{mg} / \mathrm{kg}$ of poractant alfa or $100 \mathrm{mg} / \mathrm{kg}$ of beractant for rescue therapy (A1).

5 LISA is the preferred mode of surfactant administration for spontaneously breathing babies on CPAP, provided that clinicians are experienced with this technique (B2).

6 A second and occasionally a third dose of surfactant should be given if there is ongoing evidence of RDS such as persistent high oxygen requirement and other problems have been excluded (A1).

\section{Oxygen Supplementation beyond Stabilisation}

In the last 3 years, little has changed in terms of refining previous recommendations for oxygen saturation targeting based on data from the NeOProm collaboration [83]. Targeting lower saturations (85-89 vs. 91-95\%) reduces risk of severe retinopathy of prematurity (ROP) but at expense of increasing mortality (relative risk [RR] 1.17; 95\% confidence interval [CI] 1.04-1.31) and NEC. Recommendations have therefore remained the same, targeting saturations between 90 and $94 \%$ by setting alarm limits between 89 and $95 \%$ although it is acknowledged that ideal oxygen saturation targets are still unknown [84]. Episodes of intermittent hypoxaemia and bradycardia are associated with increased risk of late death or disability at 18 months, and these should be avoided if possible [85]. Recent targeting of higher saturations is associated with an increase in need for treatment for ROP [86], and in Sweden the effect of increased risk of ROP has negated the sensitivity of poor postnatal growth for prediction of ROP [87]. Servo-controlled oxygen algorithms are now sufficiently developed to maintain saturations within targeted range more of the time both with ventilated infants and those receiving noninvasive respiratory support, although no studies have been sufficiently powered to determine if there are any beneficial effects on outcome $[88,89]$.

Recommendations

1 In preterm babies receiving oxygen, the saturation target should be between 90 and $94 \%$ (B2)

2 Alarm limits should be set to 89 and 95\% (D2).

\section{Non-Invasive Respiratory Support}

Recently, it has been emphasised that preterm infants should be managed without MV where possible and if ventilation is needed to minimise the time an endotracheal tube is used. Use of non-invasive respiratory support has increased with an expansion of methods to achieve it, but there is often a paucity of evidence to determine which method is most effective. CPAP has been used for over 40 years with early trials showing that it improves oxygenation, regulates breathing and is effective at reducing reintubation following extubation [90]. CPAP is now recommended as the optimal first mode of respiratory support although other modes of non-invasive support from birth are being tested in clinical trials [91].

CPAP involves delivering gas, ideally heated and humidified, with a measurable and controllable pressure. This pressure is transmitted using an interface such as short soft nasal prongs or mask connected tightly to the baby's face creating a seal. Pressures conveyed to the nasopharynx are typically kept between 5 and $9 \mathrm{~cm} \mathrm{H}_{2} \mathrm{O}$ providing several theoretical benefits including splinting the upper airway, maintaining lung expansion and preventing end-expiratory alveolar collapse [92]. Higher pressures improve oxygenation but potentially increase risk of air leak. Using an underwater seal to generate the pressure, or "Bubble CPAP," generates small fluctuations around the set pressure which some believe offers additional advantage [93]. Using a flow driver to generate CPAP has the theoretical advantage of offloading expira- 
tory work of breathing (the Coanda effect), although no important clinical differences have been shown among devices used to deliver CPAP, but the simplicity of bubble CPAP systems allows their use in low-income settings [94]. Trials comparing interfaces show no differences between nasal prongs and short pharyngeal tubes for initial stabilisation in the delivery room [50], but for prolonged use nasal masks may be most effective [95]. All CPAP interfaces carry a risk of facial distortion and nasal trauma. When weaning smaller babies from CPAP, gradual reduction rather than sudden cessation of pressure results in greater likelihood of weaning on the first attempt [96].

Bi-level CPAP or BIPAP is a variant of CPAP that uses small pressure differences between inspiratory and expiratory phases. These are typically delivered through CPAP flow driver devices and generate low PIP of about 9-11 cm $\mathrm{H}_{2} \mathrm{O}$ generally using fairly low rates of around 20 and long inspiratory times of about $0.8 \mathrm{~s}$. Although popular, there is no evidence that BIPAP confers any advantage over CPAP, and any clinical differences may simply reflect a higher overall mean airway pressure [97]. Modern ventilators with flow and pressure sensors also provide nasal intermittent positive pressure ventilation, or NIPPV, using pressures similar to those used for invasive MV. These breaths can be synchronised with breathing efforts using either an abdominal capsule or by detection of small pressure changes in the circuit. Recent meta-analyses of studies where NIPPV has been used as an alternative to CPAP following extubation show that it reduces need for re-ventilation and air leaks but without any reduction in BPD [98]. Synchronisation of nasal ventilation may result in the best outcomes. There is insufficient evidence to recommend NIPPV as primary mode of respiratory support in the delivery room. Nasal interfaces have also been used with high frequency oscillatory ventilation (HFOV), but results have been inconclusive $[99,100]$.

Heated humidified HFNC are increasingly used as an alternative to CPAP. With HFNC, heated/humidified gas is delivered to the nostrils with nasal catheters that are specifically designed not to occlude the nostrils, typically at flows of between 2 and $8 \mathrm{~L} / \mathrm{min}$, with weaning of flow rate determined clinically by $\mathrm{FiO}_{2}$ remaining low and judgement of work of breathing [101]. Whilst an amount of pressure is invariably generated within the nasopharynx, the primary mode of action probably relates to gas conditioning and nasopharyngeal dead space $\mathrm{CO}_{2}$ washout. In clinical trials, HFNC is broadly equivalent to CPAP for babies $>28$ weeks coming off MV with greater ease of use and less nasal trauma, although there is less evidence for smaller babies [102]. Centres familiar with

Consensus Guidelines on the

Management of RDS the use of HFNC argue that with experience it can be used for initial support even in some of the smallest babies $[103,104]$. In the HIPSTER trial, HFNC was compared with CPAP as a primary mode of support in the delivery room for infants $>28$ weeks, but the trial was stopped early because more infants started on HFNC needed rescue with CPAP [54]. At present, CPAP remains the preferred initial method of non-invasive support.

There are likely to be further refinements of non-invasive support over the next few years. Better synchronisation of ventilator support with the baby's own breathing efforts can be achieved using neurally adjusted ventilator assistance, and large clinical trials of these newer modes of support are urgently needed [105].

\section{Recommendations}

1 CPAP should be started from birth in all babies at risk of RDS, such as those $<30$ weeks' gestation who do not need intubation for stabilisation (A1).

2 The system delivering CPAP is of little importance; however, the interface should be short binasal prongs or mask with a starting pressure of about 6-8 $\mathrm{cm} \mathrm{H}_{2} \mathrm{O}$ (A2). Positive end-expiratory pressure (PEEP) can then be individualised depending on clinical condition, oxygenation and perfusion (D2).

3 CPAP with early rescue surfactant is considered optimal management for babies with RDS (A1).

4 Synchronised NIPPV, if delivered through a ventilator rather than BIPAP device, can reduce extubation failure but may not confer long-term advantages such as reduction in BPD (B2).

5 During weaning, HFNC can be used as an alternative to CPAP for some babies with the advantage of less nasal trauma (B2).

\section{Strategies}

Despite best intentions to maximise non-invasive support, many small infants will initially require $\mathrm{MV}$, and about half of those less than 28 weeks' gestation will fail their first attempt at extubation with these having higher mortality and morbidity [106]. The aim of MV is to provide "acceptable" blood gases whilst avoiding lung injury which is typically caused by too high or too low pressure delivery. The principle of MV is to inflate atelectatic lung, optimising lung volume for even distribution of tidal volumes at pressures set to prevent atelectasis and over-distension. Over-inflation increases risk of air leaks such as pneumothorax and pulmonary interstitial emphysema. Ventilation at too low a pressure risks areas of lung becoming repeatedly atelectatic during expiration, which can generate inflammation.

Modern ventilators with flow sensors can reasonably accurately measure gas volumes entering and leaving the en- 
dotracheal tube and use this information to apply limits to the amount of support delivered in order to prevent lung over-distension. Volume-targeted ventilation (VTV) enables clinicians to ventilate with less variable tidal volumes and real-time weaning of pressure as lung compliance improves. VTV compared with time-cycled pressure ventilation results in less time on the ventilator, fewer air leaks and less BPD [107]. An initial set tidal volume of about $5 \mathrm{~mL} /$ $\mathrm{kg}$ and an estimated maximum PIP according to observation of chest movement may need to be adjusted according to the baby's own respiratory efforts and gas exchange assessment. The required set tidal volume may need to be increased with increasing postnatal age if the baby remains ventilated [108]. Maintaining an "open lung" is achieved by adjusting PEEP with optimal level for a given baby being defined as that at which $\mathrm{FiO}_{2}$ is at its lowest with acceptable blood gases and haemodynamic stability [109]. Supporting the infants' own respiratory efforts with modes such as pressure support rather than synchronised intermittent mandatory ventilation also seems sensible even though no differences in clinical outcomes have been shown [110].

$\mathrm{HFOV}$ is an alternative strategy to conventional MV allowing gas exchange to be achieved using very small tidal volumes delivered at very fast rates with the lung held open at optimal inflation using a continuous distending pressure (CDP). The optimal CDP on HFOV is determined clinically by finding the pressure at which oxygenation deteriorates during stepwise reduction from full inflation and aiming for 1-2 $\mathrm{cm} \mathrm{H}_{2} \mathrm{O}$ above this [111]. Studies comparing HFOV to conventional MV show modest reductions in BPD favouring HFOV, although there is a relative paucity of trials where volume targeting is used in the conventional MV arm [112]. Volume targeting in HFOV may reduce $\mathrm{CO}_{2}$ variability and allow even lower tidal volumes to be used [113]. Neurally adjusted ventilator assistance ventilation offers the potential for better synchronisation of ventilator support with infants' own respiratory needs in real time, but further research on effectiveness of this mode is required before it can be recommended [114]. Modern ventilators now also have the option of servo-controlled oxygen delivery. This increases time spent in the desired saturation range and reduces hyperoxia, but there are no trials to show this improves outcomes $[115,116]$. Whatever ventilation mode is used within an individual unit, it is important that all staff are familiar with its use.

Once stabilised on MV and spontaneous breathing is present, clinicians should immediately consider strategies for weaning. There is no evidence favouring any particular weaning protocol [117]. Hypocarbia and severe hypercarbia are associated with worse outcomes and should be avoided by regular or continuous assessment of $\mathrm{CO}_{2}$. VTV mode enables automatic weaning of PIP in real-time as compliance improves. Some babies will only require ventilation for a very short period of time, particularly those with RDS following surfactant therapy who can be rapidly weaned to low ventilator settings. Early extubation of even the smallest babies is encouraged provided it is judged clinically safe [118]. Infant's size, absence of growth restriction, $\mathrm{FiO}_{2}$ and blood gases are all determinants of extubation success [106]. Keeping small babies on low-rate MV for longer does not improve chance of extubation success [119]. Extubation may be successful from 7 to $8 \mathrm{~cm} \mathrm{H}_{2} \mathrm{O}$ MAP on conventional modes and from 8 to $9 \mathrm{~cm} \mathrm{H}_{2} \mathrm{O} C D P$ on HFOV. Spontaneous breathing tests to predict extubation readiness are sometimes used but there is little evidence to show they are effective [120]. Extubating to a relatively higher CPAP pressure of $7-9 \mathrm{~cm} \mathrm{H}_{2} \mathrm{O}$ or NIPPV will improve chance of success [121]. Several other strategies have been used specifically to shorten duration of MV including permissive hypercarbia, caffeine therapy, postnatal steroid treatment and avoiding over-use of sedation.

\section{Permissive Hypercarbia}

Targeting arterial $\mathrm{CO}_{2}$ levels in the moderately hypercarbic range is an accepted strategy to reduce time on MV [122]. The PHELBI trial explored tolerating even higher $\mathrm{PaCO}_{2}$ up to about $10 \mathrm{kPa}$ compared to $8 \mathrm{kPa}$ in preterm babies $<29$ weeks for the first 14 days. Analysis was performed on 359 of a planned 1,534 infants after the study was stopped early, and there was no difference in the primary outcome of death or BPD but trends to worse outcomes in the higher target group [123]. Follow-up of this cohort and others suggests no long-term adverse sequelae of permissive hypercarbia and it is therefore reasonable to allow moderate elevation of $\mathrm{PaCO}_{2}$ during weaning provided the $\mathrm{pH}$ is acceptable [124].

\section{Caffeine Therapy}

Optimising success of non-invasive support involves use of caffeine therapy as a respiratory stimulant. Most information about the clinical effects of caffeine comes from the Caffeine for Apnea of Prematurity (CAP) study cohort where 2,006 babies $<1,251 \mathrm{~g}$ coming off ventilation or with apnoeic episodes were randomised to caffeine or placebo. Caffeine facilitated earlier extubation with reduction in BPD and better neurodevelopmental outcomes at 18 months $[125,126]$. In this cohort, at age 11 years the caffeine-treated children had better respiratory function [127] and reduced risk of motor impairment [128]. Caffeine prophylaxis soon after admission has become standard based 
on cohort studies showing that earlier initiation of caffeine is associated with better outcomes [129]; however, a clinical trial of prophylactic caffeine versus placebo was abandoned early because of perceived worse outcome in the caffeine-treated group [130]. The standard dosing regimen of caffeine citrate is loading with $20 \mathrm{mg} / \mathrm{kg}$ followed by maintenance of 5-10 mg/kg/day. Higher doses of up to 20 $\mathrm{mg} / \mathrm{kg} /$ day may be even more effective [131], but this needs further testing in randomised trials as higher doses are also associated with increased risk of cerebellar haemorrhage, hypertonicity and increased seizure burden [132].

\section{Postnatal Steroids}

Despite best efforts to optimise use of non-invasive support, some infants will remain on MV with the risk of lung inflammation and increased risk of BPD. Breaking this cycle using systemic corticosteroids is possible, and there are now over 50 randomised controlled trials studying the risks and benefits of various corticosteroid regimens [133, 134]. Dexamethasone increases the chance of successful extubation and reduces BPD but at the expense of increased risk of neurodevelopmental sequelae if used in the first week $[133,135]$. We previously recommended that the smallest effective dose should be used and only for babies at highest risk of BPD such as those who remain ventilatordependent after 1-2 weeks. There is anecdotal evidence that starting doses of dexamethasone as low as $0.05 \mathrm{mg} / \mathrm{kg} /$ day might be effective $[136,137]$ but the Minidex RCT failed to recruit enough participants to confirm this. Lowdose prophylactic hydrocortisone also reduced BPD [138] with improved neurological outcomes in a subgroup of infants of less than 25 weeks' gestation [139].

Inhaled budesonide seems an obvious logical alternative to systemic steroids. A recent Cochrane review of early inhaled budesonide suggests a reduction in BPD [140]. The NEUROSIS trial specifically designed and powered to answer this question confirmed that prophylactic inhaled budesonide reduces both persistent ductus arteriosus (PDA) and BPD; however, there was a worrying trend towards increased mortality before discharge [141]. Follow-up of the NEUROSIS trial cohort showed no difference in neurodevelopmental outcomes but again raised concerns about excess mortality in infants randomised to receive budesonide [142]. Meta-analysis of 17 trials of early or late inhaled corticosteroids including 1807 babies showed significant reduction in BPD (RR [95\% CI] 0.79 [0.68-0.92]) without any increase in mortality (RR [95\% CI] 1.04 [0.59-1.68]) offering reassurance that inhaled corticosteroids could be added to current management of developing BPD in preterm infants [140, 143].

Consensus Guidelines on the

Management of RDS

\section{Pain and Sedation}

Sedation and analgesia are controversial issues in RDS management [144]. The number of painful procedures experienced in the first month of life is associated with lower cognitive development and head circumference at 1 year, although this is unlikely to be direct cause and effect [145]. Whilst the comfort of the baby needs to be considered, there is a tension between appropriate analgesia and the effects of sedation causing harm particularly when there is an emphasis of minimising duration of invasive respiratory support. Laryngoscopy is undoubtedly uncomfortable, but when attempting LISA there is a better chance of achieving a success without sedation [67]. For planned non-urgent intubations, many clinicians prefer to use a combination of a short-acting opiate, muscle relaxant and atropine to maximise comfort [146] and improve chances of successful intubation [147]. Longer-acting muscle relaxants like vecuronium may increase the need for ventilation and should not be used [148]. Routine sedation of ventilated neonates with opiates or midazolam is not supported by evidence $[149,150]$. Sucrose analgesia and other non-pharmacological methods may be employed to reduce minor procedural pain [151].

Recommendations

1 After stabilisation, MV should be used in babies with RDS when other methods of respiratory support have failed (A1). Duration of MV should be minimised (B2).

2 The primary choice of ventilation mode is at discretion of clinical team; however, if conventional MV is used, targeted tidal volume ventilation should be employed (A1).

3 When weaning from MV, it is reasonable to tolerate a modest degree of hypercarbia provided the $\mathrm{pH}$ remains above 7.22 (B2).

4 Caffeine should be used to facilitate weaning from MV (A1). Early caffeine should be considered for babies at high risk of needing MV such as those on non-invasive respiratory support $(\mathbf{C 1})$.

5 A short tapering course of low dose or very low dexamethasone should be considered to facilitate extubation in babies who remain on MV after 1-2 weeks (A2).

6 Inhaled budesonide can be considered for infants at very high risk of BPD (A2).

7 Opioids should be used selectively when indicated by clinical judgment and evaluation of pain indicators (D1). The routine use of morphine or midazolam infusions in ventilated preterm infants is not recommended (A1).

\section{Monitoring and Supportive Care}

To achieve best outcomes for preterm babies with RDS, optimal supportive care with monitoring physiological variables is important. Oxygen blenders should be avail- 
able in the delivery room and in the NICU. Pulse oximetry from birth provides information of response to stabilisation. In the NICU, there should be access to continuous pulse oximetry, ECG monitoring and monitoring of $\mathrm{PaCO}_{2}$ levels. Detection of exhaled $\mathrm{CO}_{2}$ can ensure correct placement of endotracheal tubes, and continuous measurement of end-tidal $\mathrm{CO}_{2}$ also gives useful information showing trends in gas exchange. Umbilical arterial cannulation is indicated if it is anticipated there will be need for regular blood gas analyses. Transcutaneous oxygen and $\mathrm{CO}_{2}$ monitoring can also be used to access continuous information for trending but can cause skin injury especially in the most immature infants [152]. Methods of monitoring cerebral oxygenation are also available with potential to assess cerebral saturation, but no clear clinical benefit has been identified [153]. Close monitoring of serum electrolytes and haematological values is necessary ideally using micro-sampling techniques. Blood pressure should be recorded by indwelling arterial lines or intermittently using approved oscillometric devices. Aroundthe-clock access to radiology services and portable ultrasound is also essential as these are often used to confirm RDS diagnosis, exclude air leaks and confirm correct placement of endotracheal tubes and central lines.

\section{Temperature Control}

Maintaining body temperature between 36.5 and $37.5^{\circ} \mathrm{C}$ at all times is recommended [33] as hypothermia is associated with worse outcome, although it is unclear if this is direct cause and effect [154]. After birth, immediate wrapping in a polythene bag under a radiant warmer reduces heat loss [53]. Servo-controlled incubators with skin temperature set at $36.5^{\circ} \mathrm{C}$ decrease neonatal mortality [155]. Following stabilisation, infants should be nursed in incubators with high relative humidity to reduce insensible water losses. For the smallest babies, humidity of $60-80 \%$ should be used initially and reduced as skin integrity improves. Kangaroo Mother Care (KMC) is an effective means of maintaining temperature and improving outcomes in lower income settings and is increasingly being used in NICU to maximise maternal-infant bonding even in ventilated babies with the potential for benefits beyond hospital discharge $[156,157]$.

\section{Antibiotics}

Antibiotics are often started in babies with RDS until sepsis has been ruled out but policies should be in place to narrow the spectrum and minimise unnecessary exposure. Routine antibiotic prophylaxis may do more harm than good [158]. Guidelines usually offer advice on when to screen for sepsis based on additional risk factors such as maternal chorioamnionitis or early signs of septicaemia to ensure that antibiotics are only prescribed for those at greatest risk [159]. It is reasonable not to use routine antibiotics in preterm babies with RDS at low risk such as following planned delivery by elective CS. If screening is necessary, then antibiotics are started empirically whilst waiting for test results. For those who have been started empirically on antibiotics, the shortest possible course should be used and stopping after $36 \mathrm{~h}$ is achievable and considered good practice [160].

\section{Early Fluids and Nutritional Support}

The smallest infants have very high initial transcutaneous losses of water, and water and sodium move from the interstitial to the intravascular compartments making fluid balance challenging. Typically, fluids are initiated at about $70-80$ $\mathrm{mL} / \mathrm{kg} /$ day and adjustments individualised according to fluid balance, weight change and serum electrolyte levels. A modest early postnatal weight loss is normal. Regimens with more restricted fluids have better outcomes with reductions in PDA, NEC and BPD [161]. Delaying introduction of sodium supplementation until beyond the third day or $5 \%$ weight loss will also improve outcome [162]. Parenteral nutrition should be started immediately as enteral feeding is initially limited. Early initiation of higher levels of parenteral amino acids results in less postnatal growth failure and an increase in positive protein balance [163]. At least $1.5 \mathrm{~g} / \mathrm{kg}$ intravenous protein [164] and 1-2 g/kg lipids should be started from day one and increased to a maximum of $3.5 \mathrm{~g} / \mathrm{kg}$ amino acid [165]. For stable infants, a small amount $(0.5-1 \mathrm{~mL} / \mathrm{kg} / \mathrm{h})$ of breast milk can be started early to initiate enteral feeding [166]. There is no evidence of increased NEC with advancing feeds fairly rapidly up to $30 \mathrm{~mL} / \mathrm{kg} /$ day in stable VLBW babies [167]. Mother's milk is the preferred option for initiation of feeding; however, if not available then pasteurised donor breast milk is better than formula for reducing risk of NEC but will result in slower postnatal growth [168].

\section{Recommendations}

1 Core temperature should be maintained between 36.5 and $37.5^{\circ} \mathrm{C}$ at all times $(\mathrm{Cl})$.

2 Most babies should be started on intravenous fluids of 70-80 $\mathrm{mL} / \mathrm{kg} /$ day in a humidified incubator, although some very immature babies may need more (C2). Fluids must be tailored individually according to serum sodium levels, urine output and weight loss (D1).

3 Parenteral nutrition should be started from birth. Amino acids $1-2 \mathrm{~g} / \mathrm{kg} /$ day should be started from day one and quickly built up to $2.5-3.5 \mathrm{~g} / \mathrm{kg} /$ day (C2). Lipids should be started from day one and built up to a maximum of $4.0 \mathrm{~g} / \mathrm{kg} /$ day if tolerated (C2).

4 Enteral feeding with mother's milk should be started from the first day if the baby is haemodynamically stable (B2). 


\section{Managing Blood Pressure and Perfusion}

Antenatal steroids, delayed cord clamping and avoidance of MV are associated with higher mean blood pressure after birth. Hypotension and low systemic blood flow are associated with adverse long-term outcome, although thresholds for intervention and optimal treatment are unclear [169]. Blood pressure is lower with decreasing gestation and increases gradually over the first $24 \mathrm{~h}$ of life but varies widely at each gestational age [170]. Defining hypotension as a mean arterial pressure less than gestational age in weeks is widely accepted; however, many babies with RDS will breach this threshold and there is no evidence that treating "numerically defined" hypotension will influence outcome [169, 171]. Neonatologist-performed functional echocardiography is a useful adjunct to assessment of hypotension which may be related to hypovolaemia, large left-to-right ductal shunts or myocardial dysfunction, although formal governance of training for this skill is needed in Europe [172]. Hypovolaemia is probably over-diagnosed, and administration of saline boluses is associated with poorer outcomes [173]. Dopamine is more effective than dobutamine at increasing blood pressure in hypotensive infants, although dobutamine or epinephrine may be a more rational choice in the setting of reduced ventricular function [174]. Randomised trials exploring thresholds for intervention with inotropes have been unsuccessful due to poor recruitment; however, a recent observational study showed that preterm infants treated for isolated hypotension, defined as mean arterial pressure less than gestational age, had a higher survival rate raising caution about "permissive hypotension" [175]. Hydrocortisone is also a reasonable choice for extremely preterm infants with hypotension, particularly those with documented low serum cortisol [176, 177].

PDA may provide clinical problems for very preterm babies with RDS. All infants start life with an open ductus arteriosus, and most will close spontaneously. Cyclooxygenase inhibitors such as indomethacin or ibuprofen promote ductal closure, although ibuprofen has fewer side effects [178]. Paracetamol can also promote successful ductal closure perhaps with fewer renal side effects than ibuprofen [179]. Meta-analyses of all available studies suggest high-dose oral ibuprofen gives better PDA closure rates than intravenous ibuprofen or indomethacin, although no particular regimen compared with placebo influenced any important long-term outcome [180]. Routine indomethacin or ibuprofen treatment of all infants to promote PDA closure is not considered good practice [181]. Permissive tolerance of PDA is a strategy which is being studied in

Consensus Guidelines on the

Management of RDS clinical trials [182]. Surgical ligation of PDA should only be considered if medical therapy has failed and the PDA is causing significant clinical problems [183].

Maintaining a reasonable haemoglobin $(\mathrm{Hb})$ concentration is also important. Randomised trials comparing targeting more restrictive versus more liberal $\mathrm{Hb}$ concentrations (about 1-2 g/dL lower) result in reduced need for blood transfusion without affecting hospital outcomes, and recent British Committee for Standards in Haematology based their thresholds on these more restrictive thresholds [184]. However post hoc analysis of long-term follow-up data from one study showed some better cognitive outcomes in those with more liberal $\mathrm{Hb}$ thresholds highlighting the need for further studies in this area [185, 186]. It remains unclear whether a liberal or restrictive transfusion policy is best.

\section{Recommendations}

1 Treatment of hypotension is recommended when it is confirmed by evidence of poor tissue perfusion such as oliguria, acidosis and poor capillary return rather than purely on numerical values (C2).

2 If a decision is made to attempt therapeutic closure of the PDA then indomethacin, ibuprofen or paracetamol can be used (A2).

3 Haemoglobin $(\mathrm{Hb})$ concentration should be maintained within acceptable limits. Hb thresholds for infants with severe cardiopulmonary disease are $12 \mathrm{~g} / \mathrm{dL}$ (HCT 36\%), $11 \mathrm{~g} /$ $\mathrm{dL}$ (HCT $30 \%$ ) for those who are oxygen dependent and $7 \mathrm{~g} /$ dL (HCT 25\%) for stable infants beyond 2 weeks of age (C2).

\section{Miscellaneous}

Since the 2010 Guidelines, we have included a brief section on aspects of RDS management that arise infrequently. Genetic mutations affecting surfactant systems such as congenital SP-B and ABCA3 deficiency are usually fatal and beyond the scope of this guideline. Surfactant therapy may also be useful in situations where secondary surfactant inactivation occurs such as ventilated babies with severe pneumonia [187], pulmonary haemorrhage [188] or meconium aspiration syndrome [189]. There are no indications for routine or rescue use of inhaled nitric oxide (iNO) in preterm babies [190]. However, iNO continues to be used particularly in the setting of PPROM and documented pulmonary hypertension based on the observation that oxygenation can be acutely improved, although evidence for improved longer term outcomes is weak [191], and there is new evidence of an association between iNO therapy and childhood cancer [192]. Until clinical trials are completed, decisions regarding use of this expensive therapy should be taken on 
a case by case basis and treatment stopped quickly if there is no obvious response.

\section{Recommendations}

1 Surfactant can be used for RDS complicated by congenital pneumonia (C2).

2 Surfactant therapy can be used to improve oxygenation following pulmonary haemorrhage (C1).

3 Use of iNO in preterm babies should be used with caution and limited to those in clinical studies or as a therapeutic trial when there is severe documented pulmonary hypertension (D2).

\section{Disclosure Statement}

A European panel of experts was convened under the auspices of the European Society of Paediatric Research (ESPR) to update evidence-based guidelines on the management of RDS. The guidelines were prepared using evidence-based methods as summarised in Table 1. Henry Halliday and Christian Speer are or have been consultants to Chiesi Farmaceutici, Parma, the manufacturer of a leading animal-derived surfactant preparation used to treat RDS and a caffeine product for treatment of apnoea of prematurity. Virgilio Carnielli is a member of the Chiesi Farmaceutici Advisory Board. Henry Halliday and Christian Speer are joint Chief Editors of Neonatology.

\section{Appendix}

Summary of Recommendations

\begin{tabular}{|c|c|}
\hline Prenatal care & $\begin{array}{l}\text { - Preterm babies at risk of RDS should be born in centres where appropriate care including MV is available. } \\
\text { - Judicious antenatal assessment should include risk of preterm delivery and need for maternal } \\
\text { corticosteroids if risk is moderate or high. Tocolytics can be used to allow time for steroids to take effect or } \\
\text { for safe transfer where appropriate. } \\
\text { - Magnesium sulphate should be given to mothers with impending preterm delivery. }\end{array}$ \\
\hline $\begin{array}{l}\text { Delivery room } \\
\text { stabilisation }\end{array}$ & $\begin{array}{l}\text { - Aim to delay cord clamping at birth by at least } 1 \mathrm{~min} \\
\text { - Stabilise preterm babies (<28 weeks' } \mathrm{GA} \text { ) in a plastic bag under a radiant warmer to prevent heat loss. } \\
\text { Gently support breathing using CPAP if possible, and if inflations are needed avoid excessive tidal volumes. } \\
\text { Pulse oximetry can help guide heart rate response to stabilisation. Start with } 21-30 \% \text { oxygen for } 28-31 \\
\text { weeks' } \mathrm{GA} \text { and } 30 \% \text { oxygen for }<28 \text { weeks' GA and titrate up or down as needed according to } \mathrm{SpO}_{2} \text { targets. } \\
\text { Aim at } \mathrm{SpO}_{2} \text { of } 80 \% \text { or more within } 5 \text { min. } \\
\text { - Intubation at birth should be considered only for those not responding to the above, although early } \\
\text { intubation and surfactant may be required for babies who demonstrate early signs of severe RDS such as } \\
\text { chest retractions and high oxygen requirements. }\end{array}$ \\
\hline
\end{tabular}

Respiratory support and surfactant
- An animal-derived surfactant should be used and given as early as possible in the course of RDS. A treatment threshold of $\mathrm{FiO}_{2} 0.30$ on CPAP pressure of $6 \mathrm{~cm} \mathrm{H}_{2} \mathrm{O}$ seems reasonable. Repeat doses of surfactant may be required if there is ongoing evidence of RDS.

- If possible, administer surfactant using the LISA method but only if the baby is clinically stable on CPAP with worsening signs of RDS and the clinician is experienced in the technique.

- If intubated, babies can often be extubated to CPAP, HFNC or NIPPV immediately following surfactant, and judgement needs to be made if an individual baby will tolerate this.

- For those who require MV, aim to ventilate for as short a time as possible avoiding hyperoxia, hypocarbia and volutrauma. This may be best achieved with volume-targeted ventilation and saturation alarm limits set at 89 and $95 \%$.

- Caffeine therapy should be used routinely to minimise need for ventilation. Babies should be maintained on non-invasive respiratory support in preference to MV if possible. After 1-2 weeks, systemic steroids should be considered to facilitate extubation if the baby remains ventilated.

- In preterm babies receiving oxygen, the saturation target should be between 90 and $94 \%$. To achieve this, suggested alarm limits should be 89 and $95 \%$.

\begin{tabular}{|c|c|}
\hline $\begin{array}{l}\text { Supportive } \\
\text { care }\end{array}$ & 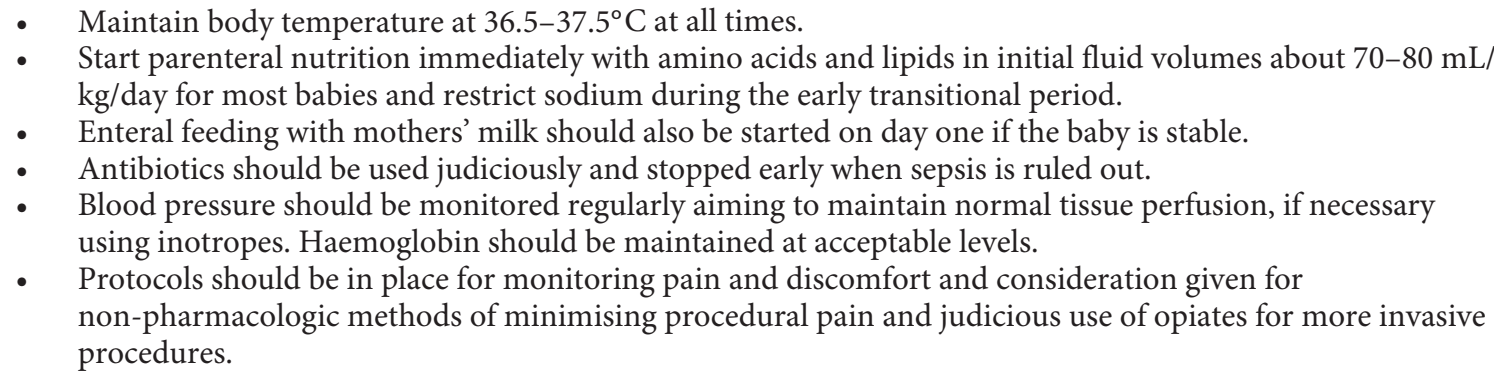 \\
\hline
\end{tabular}




\section{References}

1 Stoll BJ, Hansen NI, Bell EF, Walsh MC, Carlo WA, Shankaran S, et al.; Eunice Kennedy Shriver National Institute of Child Health and Human Development Neonatal Research Network. Trends in Care Practices, Morbidity, and Mortality of Extremely Preterm Neonates, 1993-2012. JAMA. 2015 Sep;314(10): 1039-51.

2 Sweet D, Bevilacqua G, Carnielli V, Greisen G, Plavka R, Saugstad OD, et al.; European Association of Perinatal Medicine. European consensus guidelines on the management of neonatal respiratory distress syndrome. J Perinat Med. 2007;35(3):175-86.

3 Sweet DG, Carnielli V, Greisen G, Hallman M, Ozek E, Plavka R, et al.; European Association of Perinatal Medicine. European consensus guidelines on the management of neonatal respiratory distress syndrome in preterm infants - 2010 update. Neonatology. 2010 Jun;97(4):402-17.

4 Sweet DG, Carnielli V, Greisen G, Hallman M, Ozek E, Plavka R, et al.; European Association of Perinatal Medicine. European consensus guidelines on the management of neonatal respiratory distress syndrome in preterm infants-2013 update. Neonatology. 2013;103(4):353-68.

5 Sweet DG, Carnielli V, Greisen G, Hallman M, Ozek E, Plavka R, et al. European consensus guidelines on the management of respiratory distress syndrome - 2016 update. Neonatology. 2017;111(2):107-25.

6 Sweet DG, Carnielli V, Greisen G, Hallman M, Ozek E, Plavka R, et al. European Association of Perinatal Medicine [European consensus guidelines on the management of neonatal respiratory distress syndrome in preterm infants-2013 update]. Zhonghua Er Ke Za Zhi. 2014;52:749-55.

7 https://nightingale.vtoxford.org/reports.aspx

8 Guyatt GH, Oxman AD, Kunz R, Falck-Ytter Y, Vist GE, Liberati A, et al.; GRADE Working Group. Going from evidence to recommendations. BMJ. 2008 May;336(7652): 1049-51.

9 Diguisto C, Foix L'Helias L, Morgan AS, Ancel PY, Kayem G, Kaminski M, et al. Neonatal outcomes in extremely preterm newborns admitted to intensive care after no active antenatal management: a population-based cohort study. J Pediatr. 2018 Dec;203:150-5.

10 Vintzileos AM, Visser GH. Interventions for women with mid-trimester short cervix: which ones work? [editorial]. Ultrasound Obstet Gynecol. 2017 Mar;49(3):295-300.

11 Jarde A, Lutsiv O, Beyene J, McDonald SD. Vaginal progesterone, oral progesterone, 17 OHPC, cerclage, and pessary for preventing preterm birth in at-risk singleton pregnancies: an updated systematic review and network meta-analysis. BJOG. 2019 Apr;126(5): 556-567.
12 McIntosh J, Feltovich H, Berghella V, Manuck T; Society for Maternal-Fetal Medicine (SMFM). McIntosh J, Feltovich H, Berghella $\mathrm{V}$, Manuck T: The role of routine cervical length screening in selected high- and lowrisk women for preterm birth prevention. Am J Obstet Gynecol. 2016;215(3):B2-7.

13 Alfirevic Z, Stampalija T, Medley N. Cervical stitch (cerclage) for preventing preterm birth in singleton pregnancy. Cochrane Database Syst Rev. 2017 Jun;6:CD008991.

14 Son M, Miller ES. Predicting preterm birth: cervical length and fetal fibronectin. Semin Perinatol. 2017 Dec;41(8):445-51.

15 Marlow N, Bennett C, Draper ES, Hennessy EM, Morgan AS, Costeloe KL. Perinatal outcomes for extremely preterm babies in relation to place of birth in England: the EPICure 2 study. Arch Dis Child Fetal Neonatal Ed. 2014 May;99(3):F181-8.

16 Kenyon S, Boulvain M, Neilson JP. Antibiotics for preterm rupture of membranes. Cochrane Database Syst Rev. 2013 Dec;(12): CD001058.

17 Doyle LW, Crowther CA, Middleton P, Marret S, Rouse D. Magnesium sulphate for women at risk of preterm birth for neuroprotection of the fetus. Cochrane Database Syst Rev. 2009 Jan;1(1):CD004661.

18 Doyle LW, Anderson PJ, Haslam R, Lee KJ, Crowther C; Australasian Collaborative Trial of Magnesium Sulphate (ACTOMgSO4) Study Group. School-age outcomes of very preterm infants after antenatal treatment with magnesium sulfate vs placebo. JAMA. 2014 Sep;312(11):1105-13.

19 Haas DM, Caldwell DM, Kirkpatrick P, McIntosh JJ, Welton NJ. Tocolytic therapy for preterm delivery: systematic review and network meta-analysis. BMJ. 2012 Oct;345 oct09 2:e6226.

20 Royal College of Obstetricians and Gynaecologists. Tocolysis for women in preterm labour. Green-top Guideline No. 1b. February 2011. https://www.rcog.org.uk/globalassets/ documents/guidelines/gtg_1b.pdf.

21 Roberts D, Brown J, Medley N, Dalziel SR. Antenatal corticosteroids for accelerating fetal lung maturation for women at risk of preterm birth. Cochrane Database Syst Rev. 2017 Mar;3:CD004454.

22 Ehret DE, Edwards EM, Greenberg LT, Bernstein IM, Buzas JS, Soll RF, et al. Association of antenatal steroid exposure with survival among infants receiving postnatal life support at 22 to 25 weeks' gestation. JAMA Netw Open. 2018 Oct;1(6):e183235.

23 Gyamfi-Bannerman C, Thom EA, Blackwell SC, Tita AT, Reddy UM, Saade GR, et al.; NICHD Maternal-Fetal Medicine Units Network. Antenatal betamethasone for women at risk for late preterm delivery. N Engl J Med. 2016 Apr;374(14):1311-20.
24 Stutchfield PR, Whitaker R, Gliddon AE, Hobson L, Kotecha S, Doull IJ. Behavioural, educational and respiratory outcomes of antenatal betamethasone for term caesarean section (ASTECS trial). Arch Dis Child Fetal Neonatal Ed. 2013 May;98(3):F195-200.

25 Kamath-Rayne BD, Rozance PJ, Goldenberg $\mathrm{RL}$, Jobe AH. Antenatal corticosteroids beyond 34 weeks gestation: what do we do now? Am J Obstet Gynecol. 2016 Oct;215(4):42330.

26 Sotiriadis A, Makrydimas G, Papatheodorou S, Ioannidis JP, McGoldrick E. Corticosteroids for preventing neonatal respiratory morbidity after elective caesarean section at term. Cochrane Database Syst Rev. 2018 Aug; 8:CD006614.

27 Norman M, Piedvache A, Børch K, Huusom LD, Bonamy AE, Howell EA, et al.; Effective Perinatal Intensive Care in Europe (EPICE) Research Group. Association of short antenatal corticosteroid administration-to-birth intervals with survival and morbidity among very preterm infants: results from the EPICE cohort. JAMA Pediatr. 2017 Jul;171(7):67886.

28 Crowther CA, McKinlay CJ, Middleton P, Harding JE. Repeat doses of prenatal corticosteroids for women at risk of preterm birth for improving neonatal health outcomes. Cochrane Database Syst Rev. 2015 Jul;7(7): CD003935.

29 Cartwright RD, Crowther CA, Anderson PJ, Harding JE, Doyle LW, McKinlay CJ. Association of fetal growth restriction with neurocognitive function after repeated antenatal betamethasone treatment vs placebo: secondary analysis of the ACTORDS randomized clinical trial. JAMA Netw Open. 2019 Feb; 2(2):e187636

30 WHO. WHO recommendations on interventions to improve preterm birth outcomes. Geneva: WHO; 2015.

31 Asztalos, Murphy KE, Willan AR, Matthews SG, Ohlsson A, Saigal S, et al: Multiple courses of antenatal corticosteroids for preterm birth study: outcomes in children at 5 years of age (MACS-5). JAMA Pediatr 2013; 167: 1102-1110.

32 Besnard AE, Wirjosoekarto SA, Broeze KA, Opmeer BC, Mol BW. Lecithin/sphingomyelin ratio and lamellar body count for fetal lung maturity: a meta-analysis. Eur J Obstet Gynecol Reprod Biol. 2013 Jul;169(2):177-83.

33 Wyllie J, Bruinenberg J, Roehr CC, Rüdiger M, Trevisanuto D, Urlesberger B. European Resuscitation Council Guidelines for Resuscitation 2015: Section 7. Resuscitation and support of transition of babies at birth. Resuscitation. 2015 Oct;95:249-63.

34 O’Donnell CP, Kamlin CO, Davis PG, Morley CJ. Crying and breathing by extremely preterm infants immediately after birth. J Pediatr. 2010 May;156(5):846-7. 
35 Saugstad OD. Delivery room management of term and preterm newly born infants. Neonatology. 2015;107(4):365-71.

36 Polglase GR, Dawson JA, Kluckow M, Gill AW, Davis PG, Te Pas AB, et al. Ventilation onset prior to umbilical cord clamping (physiological-based cord clamping) improves systemic and cerebral oxygenation in preterm lambs. PLoS One. 2015 Feb;10(2):e0117504.

37 Tarnow-Mordi W, Morris J, Kirby A, Robledo K, Askie L, Brown R, et al.; Australian Placental Transfusion Study Collaborative Group. Delayed versus immediate cord clamping in preterm infants. N Engl J Med. 2017 Dec;377(25):2445-55.

38 Fogarty M, Osborn DA, Askie L, Seidler AL, Hunter K, Lui K, et al. Delayed vs early umbilical cord clamping for preterm infants: a systematic review and meta-analysis. Am J Obstet Gynecol. 2018 Jan;218(1):1-18.

39 Duley L, Dorling J, Pushpa-Rajah A, Oddie SJ, Yoxall CW, Schoonakker B, et al.; Cord Pilot Trial Collaborative Group. Randomised trial of cord clamping and initial stabilisation at very preterm birth. Arch Dis Child Fetal Neonatal Ed. 2018 Jan;103(1):F6-14

40 Patel S, Clark EA, Rodriguez CE, Metz TD, Abbaszadeh M, Yoder BA. Effect of umbilical cord milking on morbidity and survival in extremely low gestational age neonates. Am J Obstet Gynecol. 2014 Nov;211(5):519.e1-7.

41 Nagano N, Saito M, Sugiura T, Miyahara F, Namba F, Ota E. Benefits of umbilical cord milking versus delayed cord clamping on neonatal outcomes in preterm infants: A systematic review and meta-analysis. PLoS One. 2018 Aug;13(8):e0201528.

42 Katheria A, Garey D, Truong G, Akshoomoff $\mathrm{N}$, Steen J, Maldonado M, et al. A randomized clinical trial of umbilical cord milking vs delayed cord clamping in preterm infants: neurodevelopmental outcomes at 22-26 months of corrected age. J Pediatr. 2018 Mar;194:7680.

43 Katheria AC, Reister F, Hummler H, Essers J, Mendler M, Truong G, et al. Premature Infants Receiving Cord Milking or Delayed Cord Clamping: A Randomized Controlled Non-inferiority Trial (abstract LB 1). Am J Obstet Gynecol 2019 Jan;220(Suppl):S682.

44 Dekker J, Hooper SB, Martherus T, Cramer SJ, van Geloven N, Te Pas AB. Repetitive versus standard tactile stimulation of preterm infants at birth - A randomized controlled trial. Resuscitation. 2018 Jun;127:37-43.

45 Schmölzer GM, Kumar M, Pichler G, Aziz K, O’Reilly M, Cheung PY. Non-invasive versus invasive respiratory support in preterm infants at birth: systematic review and metaanalysis. BMJ. 2013 Oct; 347 oct17 3:f5980.

46 Kelleher J, Bhat R, Salas AA, Addis D, Mills EC, Mallick H, et al. Oronasopharyngeal suction versus wiping of the mouth and nose at birth: a randomised equivalency trial. Lancet. 2013 Jul;382(9889):326-30.
47 Fischer HS, Schmölzer GM, Cheung PY, Büh rer C. Sustained inflations and avoiding mechanical ventilation to prevent death or bronchopulmonary dysplasia: a meta-analysis. Eur Respir Rev. 2018 Nov;27(150):180083.

48 Kirpalani H, Ratcliffe S, Keszler M, et al. The international "Sustained Aeration for Infant Lung" (SAIL) randomized trial. Presented at the Pediatric Academic Societies meeting, May 5-8, 2018, Toronto. Abstract 1852.1.

49 Szyld E, Aguilar A, Musante GA, Vain N, Prudent L, Fabres J, et al.; Delivery Room Ventilation Devices Trial Group. Comparison of devices for newborn ventilation in the delivery room. J Pediatr. 2014 Aug;165(2):234-239.e3.

50 McCarthy LK, Twomey AR, Molloy EJ, Murphy JF, O’Donnell CP. A randomized trial of nasal prong or face mask for respiratory support for preterm newborns. Pediatrics. 2013 Aug;132(2):e389-95.

51 Jobe AH, Ikegami M. Mechanisms initiating lung injury in the preterm. Early Hum Dev. 1998 Nov;53(1):81-94.

52 Meyer MP, Owen LS, Te Pas AB. Use of heated humidified gases for early stabilization of preterm infants: a meta-analysis. Front Pediatr. 2018 Oct; $6: 319$.

53 McCall EM, Alderdice F, Halliday HL, Vohra $\mathrm{S}$, Johnston L. Interventions to prevent hypothermia at birth in preterm and/or low birth weight infants. Cochrane Database Syst Rev. 2018 Feb;2:CD004210

54 Roberts CT, Owen LS, Manley BJ, Frøisland DH, Donath SM, Dalziel KM, et al.; HIPSTER Trial Investigators. Nasal high-flow therapy for primary respiratory support in preterm infants. N Engl J Med. 2016 Sep;375(12): 1142-51.

55 Kapadia VS, Oei JL, Saugstad OD, Rabi Y, Finer NN, Tarnow-Mordi W et al: BradyPrem study: heart rate is the most vital signs during resuscitation of preterms. EPAS-2018: 4650.4.

56 Phillipos E, Solevåg AL, Pichler G, Aziz K, van Os S, O'Reilly M, et al. Heart rate assessment immediately after birth. Neonatology. 2016; 109(2):130-8

57 Welsford M, Nishiyama C, Shortt C, Isayama T, Dawson JA, Weiner G, et al.; International Liaison Committee on Resuscitation Neonatal Life Support Task Force. Room air for initiating term newborn resuscitation: a systematic review with meta-analysis. Pediatrics. 2019 Jan;143(1):e20181825.

58 Lui K, Jones LJ, Foster JP, Davis PG, Ching SK, Oei JL, et al. Lower versus higher oxygen concentrations titrated to target oxygen saturations during resuscitation of preterm infants at birth. Cochrane Database Syst Rev. 2018 May;5:CD010239.

59 Lamberska T, Luksova M, Smisek J, Vankova J, Plavka R. Premature infants born at $[\{\mathrm{LT}\}] 25$ weeks of gestation may be compromised by currently recommended resuscitation techniques. Acta Paediatr. 2016 Apr; 105(4):e142-50.
60 Oei JL, Finer NN, Saugstad OD, Wright IM, Rabi Y, Tarnow-Mordi W, et al. Outcomes of oxygen saturation targeting during delivery room stabilisation of preterm infants. Arch Dis Child Fetal Neonatal Ed. 2018 Sep; 103(5):F446-54.

61 Welsford M, Nishiyama C, Shortt C, Weiner $\mathrm{G}$, Roehr CC, Isayama T, et al.; International Liaison Committee on Resuscitation Neonatal Life Support Task Force. Initial oxygen use for preterm newborn resuscitation: a systematic review with meta-analysis. Pediatrics. 2019 Jan;143(1):e20181828.

62 Saugstad OD, Oei JL, Lakshminrusimha S, Vento M. Oxygen therapy of the newborn from molecular understanding to clinical practice. Pediatr Res. 2019 Jan;85(1):20-9.

63 Soll RF, Morley CJ. Prophylactic versus selective use of surfactant in preventing morbidity and mortality in preterm infants. Cochrane Database Syst Rev. 2001;2(2):CD000510.

64 Stevens TP, Harrington EW, Blennow M, Soll RF. Early surfactant administration with brief ventilation vs. selective surfactant and continued mechanical ventilation for preterm infants with or at risk for respiratory distress syndrome. Cochrane Database Syst Rev. 2007 Oct;4(4):CD003063

65 Aldana-Aguirre JC, Pinto M, Featherstone RM, Kumar M. Less invasive surfactant administration versus intubation for surfactant delivery in preterm infants with respiratory distress syndrome: a systematic review and meta-analysis. Arch Dis Child Fetal Neonatal Ed. 2017 Jan;102(1):F17-23.

66 Klebermass-Schrehof K, Wald M, Schwindt J, Grill A, Prusa AR, Haiden N, et al. Less invasive surfactant administration in extremely preterm infants: impact on mortality and morbidity. Neonatology. 2013;103(4):252-8.

67 Dekker J, Lopriore E, van Zanten HA, Tan $\mathrm{RN}$, Hooper SB, Te Pas AB. Sedation during minimal invasive surfactant therapy: a randomised controlled trial. Arch Dis Child Fetal Neonatal Ed. doi: 10.1136/archdischild2018-315015

68 Minocchieri S, Berry CA, Pillow JJ; CureNeb Study Team: Nebulised surfactant to reduce severity of respiratory distress: a blinded, parallel, randomised controlled trial. Arch Dis Child Fetal Neonatal Ed. doi: 10.1136/archdischild2018-315051.

69 Roberts KD, Brown R, Lampland AL, Leone TA, Rudser KD, Finer NN, et al. Laryngeal mask airway for surfactant administration in neonates: a randomized, controlled trial. J Pediatr. 2018 Feb;193:40-46.e1.

70 Bansal SC, Caoci S, Dempsey E, Trevisanuto $\mathrm{D}$, Roehr CC. The laryngeal mask airway and its use in neonatal resuscitation: a critical review of where we are in 2017/2018. Neonatology. 2018;113(2):152-61.

71 Bahadue FL, Soll R. Early versus delayed selective surfactant treatment for neonatal respiratory distress syndrome. Cochrane Database Syst Rev. 2012 Nov;11:CD001456. 
72 Verder H, Albertsen P, Ebbesen F, Greisen G, Robertson B, Bertelsen A, et al. Nasal continuous positive airway pressure and early surfactant therapy for respiratory distress syndrome in newborns of less than 30 weeks' gestation. Pediatrics. 1999 Feb;103(2):E24.

73 De Martino L, Yousef N, Ben-Ammar R, Raimondi F, Shankar-Aguilera S, De Luca D. Lung ultrasound score predicts surfactant need in extremely preterm neonates. Pediatrics. 2018 Sep;142(3):e20180463.

74 Escourrou G, De Luca D. Lung ultrasound decreased radiation exposure in preterm infants in a neonatal intensive care unit. Acta Paediatr. 2016 May;105(5):e237-9.

75 Verder H, Heiring C, Clark H, Sweet D, Jessen TE, Ebbesen F, et al. Rapid test for lung maturity, based on spectroscopy of gastric aspirate, predicted respiratory distress syndrome with high sensitivity. Acta Paediatr. 2017 Mar; 106(3):430-7.

76 Dargaville PA, Aiyappan A, De Paoli AG, Dalton RG, Kuschel CA, Kamlin CO, et al. Continuous positive airway pressure failure in preterm infants: incidence, predictors and consequences. Neonatology. 2013;104(1):814.

77 Singh N, Halliday HL, Stevens TP, Suresh G, Soll R, Rojas-Reyes MX. Comparison of animal-derived surfactants for the prevention and treatment of respiratory distress syndrome in preterm infants. Cochrane Database Syst Rev. 2015 Dec;(12):CD010249.

78 Dani C, Corsini I, Poggi C. Risk factors for intubation-surfactant-extubation (INSURE) failure and multiple INSURE strategy in preterm infants. Early Hum Dev. 2012 Mar;88 Suppl 1:S3-4.

79 Brix N, Sellmer A, Jensen MS, Pedersen LV, Henriksen TB. Predictors for an unsuccessful INtubation-SURfactant-Extubation procedure: a cohort study. BMC Pediatr. 2014 Jun; 14(1): 155 .

80 Sweet DG, Turner MA, Straňák Z, Plavka R, Clarke P, Stenson BJ, et al. A first-in-human clinical study of a new SP-B and SP-C enriched synthetic surfactant (CHF5633) in preterm babies with respiratory distress syndrome. Arch Dis Child Fetal Neonatal Ed. 2017 Nov;102(6):F497-503.

81 Venkataraman R, Kamaluddeen M, Hasan SU, Robertson HL, Lodha A. Intratracheal administration of budesonide-surfactant in prevention of bronchopulmonary dysplasia in very low birth weight infants: a systematic review and meta-analysis. Pediatr Pulmonol. 2017 Jul;52(7):968-75.

82 Bancalari E, Jain D, Jobe AH. Prevention of bronchopulmonary dysplasia: are intratracheal steroids with surfactant a magic bullet? Am J Respir Crit Care Med. 2016 Jan;193(1): $12-3$.
83 Askie LM, Darlow BA, Finer N, Schmidt B, Stenson B, Tarnow-Mordi W, et al.; Neonatal Oxygenation Prospective Meta-analysis (NeOProM) Collaboration. Association between oxygen saturation targeting and death or disability in extremely preterm infants in the Neonatal Oxygenation Prospective Metaanalysis Collaboration. JAMA. 2018 Jun; 319(21):2190-201.

84 Saugstad OD. Oxygenation of the immature infant: a commentary and recommendations for oxygen saturation targets and alarm limits. Neonatology. 2018;114(1):69-75.

85 Poets CF, Roberts RS, Schmidt B, Whyte RK, Asztalos EV, Bader D, et al.; Canadian Oxygen Trial Investigators. Association between intermittent hypoxemia or bradycardia and late death or disability in extremely preterm infants. JAMA. 2015 Aug;314(6):595-603.

86 Manley BJ, Kuschel CA, Elder JE, Doyle LW, Davis PG. Higher rates of retinopathy of prematurity after increasing oxygen saturation targets for very preterm infants: experience in a single center. J Pediatr. 2016 Jan;168:242-4.

87 Lundgren $\mathrm{P}$, Hård AL, Wilde Å, Löfqvist C, Smith LE, Hellström A. Implementing higher oxygen saturation targets reduced the impact of poor weight gain as a predictor for retinopathy of prematurity. Acta Paediatr. 2018 May; 107(5):767-73.

88 Gajdos M, Waitz M, Mendler MR, Braun W, Hummler H. Effects of a new device for automated closed loop control of inspired oxygen concentration on fluctuations of arterial and different regional organ tissue oxygen saturations in preterm infants. Arch Dis Child Fetal Neonatal Ed. https://doi.org/10.1136/archdischild-2018-314769.

89 Reynolds PR, Miller TL, Volakis LI, Holland N, Dungan GC, Roehr CC, et al. Randomised cross-over study of automated oxygen control for preterm infants receiving nasal high flow. Arch Dis Child Fetal Neonatal Ed. https://doi. org/10.1136/archdischild-2018-315342.

90 Davis PG, Henderson-Smart DJ. Nasal continuous positive airways pressure immediately after extubation for preventing morbidity in preterm infants. Cochrane Database Syst Rev. 2003;2(2):CD000143.

91 Subramaniam P, Ho JJ, Davis PG. Prophylactic nasal continuous positive airway pressure for preventing morbidity and mortality in very preterm infants. Cochrane Database Syst Rev. 2016 Jun;6(6):CD001243.

92 Davis PG, Morley CJ, Owen LS. Non-invasive respiratory support of preterm neonates with respiratory distress: continuous positive airway pressure and nasal intermittent positive pressure ventilation. Semin Fetal Neonatal Med. 2009 Feb;14(1):14-20

93 Welty SE. Continuous positive airway pressure strategies with bubble nasal continuous positive airway pressure: not all bubbling is the same: the Seattle Positive Airway Pressure System. Clin Perinatol. 2016 Dec;43(4):66171.
94 Mazmanyan P, Mellor K, Doré CJ, Modi N A randomised controlled trial of flow driver and bubble continuous positive airway pressure in preterm infants in a resourcelimited setting. Arch Dis Child Fetal Neonatal Ed. 2016 Jan;101(1):F16-20.

95 Say B, Kanmaz Kutman HG, Oguz SS, Oncel MY, Arayici S, Canpolat FE, et al. Binasal prong versus nasal mask for applying CPAP to preterm infants: a randomized controlled trial. Neonatology. 2016;109(4):258-64.

96 Jensen CF, Sellmer A, Ebbesen F, Cipliene $\mathrm{R}$, Johansen A, Hansen RM, et al. Sudden vs pressure wean from nasal continuous positive airway pressure in infants born before 32 weeks of gestation: a randomized clinical trial. JAMA Pediatr. 2018 Sep;172(9):82431.

97 Lampland AL, Plumm B, Worwa C, Meyers P, Mammel MC. Bi-level CPAP does not improve gas exchange when compared with conventional CPAP for the treatment of neonates recovering from respiratory distress syndrome. Arch Dis Child Fetal Neonatal Ed. 2015 Jan;100(1):F31-4.

98 Lemyre B, Davis PG, De Paoli AG, Kirpalani $\mathrm{H}$. Nasal intermittent positive pressure ventilation (NIPPV) versus nasal continuous positive airway pressure (NCPAP) for preterm neonates after extubation. Cochrane Database Syst Rev. 2017 Feb;2:CD003212.

99 Bottino R, Pontiggia F, Ricci C, Gambacorta A, Paladini A, Chijenas V, et al. Nasal highfrequency oscillatory ventilation and $\mathrm{CO} 2$ removal: A randomized controlled crossover trial. Pediatr Pulmonol. 2018 Sep; 53(9):1245-51.

100 Klotz D, Schneider H, Schumann S, Mayer B, Fuchs H. Non-invasive high-frequency oscillatory ventilation in preterm infants: a randomised controlled cross-over trial. Arch Dis Child Fetal Neonatal Ed. 2018 Jul; 103(4):F1-5.

101 Roehr CC, Yoder BA, Davis PG, Ives K. Evidence support and guidelines for using heated, humidified, high-flow nasal cannulae in neonatology: Oxford Nasal HighFlow Therapy Meeting, 2015. Clin Perinatol. 2016 Dec;43(4):693-705.

102 Wilkinson D, Andersen C, O'Donnell CP, De Paoli AG, Manley BJ. High flow nasal cannula for respiratory support in preterm infants. Cochrane Database Syst Rev. 2016 Feb;2:CD006405.

103 Zivanovic S, Scrivens A, Panza R, Reynolds $\mathrm{P}$, Laforgia $\mathrm{N}$, Ives KN, et al. Nasal high-flow therapy as primary respiratory support for preterm infants without the need for rescue with nasal continuous positive airway pressure. Neonatology. 2019;115(2):175-81.

104 Reynolds P, Leontiadi S, Lawson T, Otunla T, Ejiwumi O, Holland N. Stabilisation of premature infants in the delivery room with nasal high flow. Arch Dis Child Fetal Neonatal Ed. 2016 Jul;101(4):F284-7.
Consensus Guidelines on the

Management of RDS
Neonatology 2019;115:432-450

DOI: $10.1159 / 000499361$ 
105 Firestone KS, Beck J, Stein H. Neurally adjusted ventilatory assist for non-invasive support in neonates. Clin Perinatol. 2016 Dec;43(4):707-24.

106 Chawla S, Natarajan G, Shankaran S, Carper B, Brion LP, Keszler M, et al.; Eunice Kennedy Shriver National Institute of Child Health and Human Development Neonatal Research Network. Markers of successful extubation in extremely preterm infants, and morbidity after failed extubation. J Pediatr. 2017 Oct;189:113-119.e2.

107 Klingenberg C, Wheeler KI, McCallion N, Morley CJ, Davis PG. Volume-targeted versus pressure-limited ventilation in neonates. Cochrane Database Syst Rev. 2017 Oct;10:CD003666.

108 Keszler M, Nassabeh-Montazami S, Abubakar K. Evolution of tidal volume requirement during the first 3 weeks of life in infants $[\{\mathrm{LT}\}] 800 \mathrm{~g}$ ventilated with Volume Guarantee. Arch Dis Child Fetal Neonatal Ed. 2009 Jul;94(4):F279-82.

109 Rimensberger PC, Cox PN, Frndova H, Bryan AC. The open lung during small tidal volume ventilation: concepts of recruitment and "optimal" positive end-expiratory pressure. Crit Care Med. 1999 Sep;27(9):194652.

110 Unal S, Ergenekon E, Aktas S, Altuntas N, Beken S, Kazanci E, et al. Effects of volume guaranteed ventilation combined with two different modes in preterm infants. Respir Care. 2017 Dec;62(12):1525-32.

111 De Jaegere A, van Veenendaal MB, Michiels A, van Kaam AH. Lung recruitment using oxygenation during open lung high-frequency ventilation in preterm infants. Am J Respir Crit Care Med. 2006 Sep;174(6):639_ 45.

112 Cools F, Offringa M, Askie LM. Elective high frequency oscillatory ventilation versus conventional ventilation for acute pulmonary dysfunction in preterm infants. Cochrane Database Syst Rev. 2015 Mar;3(3): CD000104.

113 Iscan B, Duman N, Tuzun F, Kumral A, Ozkan H. Impact of volume guarantee on highfrequency oscillatory ventilation in preterm infants: a randomized crossover clinical trial. Neonatology. 2015;108(4):277-82.

114 Rossor TE, Hunt KA, Shetty S, Greenough A. Neurally adjusted ventilatory assist compared to other forms of triggered ventilation for neonatal respiratory support. Cochrane Database Syst Rev. 2017 Oct;10:CD012251.

115 Van Zanten HA, Kuypers KL, Stenson BJ, Bachman TE, Pauws SC, Te Pas AB. The effect of implementing an automated oxygen control on oxygen saturation in preterm infants. Arch Dis Child Fetal Neonatal Ed. 2017 Sep;102(5):F395-9.
116 Mitra S, Singh B, El-Naggar W, McMillan DD. Automated versus manual control of inspired oxygen to target oxygen saturation in preterm infants: a systematic review and meta-analysis. J Perinatol. 2018 Apr;38(4): 351-60.

117 Ferguson KN, Roberts CT, Manley BJ, Davis PG. Interventions to improve rates of successful extubation in preterm infants: a systematic review and meta-analysis. JAMA Pediatr. 2017 Feb;171(2):165-74.

118 Manley BJ, Doyle LW, Owen LS, Davis PG. Extubating extremely preterm infants: predictors of success and outcomes following failure. J Pediatr. 2016 Jun;173:45-9.

119 Danan C, Durrmeyer X, Brochard L, Decobert F, Benani M, Dassieu G. A randomized trial of delayed extubation for the reduction of reintubation in extremely preterm infants. Pediatr Pulmonol. 2008 Feb; 43(2):117-24.

120 Shalish W, Latremouille S, Papenburg J, Sant'Anna GM. Predictors of extubation readiness in preterm infants: a systematic review and meta-analysis. Arch Dis Child Fetal Neonatal Ed. 2019 Jan;104(1):F89-97.

121 Buzzella B, Claure N, D’Ugard C, Bancalari E. A randomized controlled trial of two nasal continuous positive airway pressure levels after extubation in preterm infants. J Pediatr. 2014 Jan;164(1):46-51

122 Woodgate PG, Davies MW. Permissive hypercapnia for the prevention of morbidity and mortality in mechanically ventilated newborn infants. Cochrane Database Syst Rev. 2001;2(2):CD002061.

123 Thome UH, Genzel-Boroviczeny O, Bohnhorst B, Schmid M, Fuchs H, Rohde O, et al.; PHELBI Study Group. Permissive hypercapnia in extremely low birthweight infants (PHELBI): a randomised controlled multicentre trial. Lancet Respir Med. 2015 Jul; 3(7):534-43.

124 Thome UH, Genzel-Boroviczeny O, Bohnhorst B, Schmid M, Fuchs H, Rohde O, et al.; PHELBI Study Group. Neurodevelopmental outcomes of extremely low birthweight infants randomised to different $\mathrm{PCO} 2$ targets: the PHELBI follow-up study. Arch Dis Child Fetal Neonatal Ed. 2017 Sep; 102(5):F376-82.

125 Schmidt B, Roberts RS, Davis P, Doyle LW, Barrington KJ, Ohlsson A, et al.; Caffeine for Apnea of Prematurity Trial Group. Caffeine therapy for apnea of prematurity. N Engl J Med. 2006 May;354(20):2112-21.

126 Schmidt B, Roberts RS, Davis P, Doyle LW, Barrington KJ, Ohlsson A, et al.; Caffeine for Apnea of Prematurity Trial Group. Longterm effects of caffeine therapy for apnea of prematurity. N Engl J Med. 2007 Nov; 357(19):1893-902.

127 Doyle LW, Ranganathan S, Cheong JL. Neonatal caffeine treatment and respiratory function at 11 years in children under 1,251 $\mathrm{g}$ at birth. Am J Respir Crit Care Med. 2017 Nov;196(10):1318-24.
128 Schmidt B, Roberts RS, Anderson PJ, Asztalos EV, Costantini L, Davis PG, et al.; Caffeine for Apnea of Prematurity (CAP) Trial Group. Academic performance, motor function, and behavior 11 years after neonatal caffeine citrate therapy for apnea of prematurity: an 11-year follow-up of the CAP randomized clinical trial. JAMA Pediatr. 2017 Jun;171(6):564-72.

129 Lodha A, Entz R, Synnes A, Creighton D, Yusuf K, Lapointe A, et al.; Investigators of the Canadian Neonatal Network (CNN) and the Canadian Neonatal Follow-up Network (CNFUN). Early caffeine administration and neurodevelopmental outcomes in preterm infants. Pediatrics. 2019 Jan; 143(1):e20181348.

130 Amaro CM, Bello JA, Jain D, Ramnath A, D'Ugard C, Vanbuskirk S, et al. Early caffeine and weaning from mechanical ventilation in preterm infants: a randomized, placebo-controlled trial. J Pediatr. 2018 May; 196:52-7.

131 Vliegenthart R, Miedema M, Hutten GJ, van Kaam AH, Onland W. High versus standard dose caffeine for apnoea: a systematic review. Arch Dis Child Fetal Neonatal Ed. 2018 Nov;103(6):F523-9.

132 Vesoulis ZA, McPherson C, Neil JJ, Mathur AM, Inder TE. Early high-dose caffeine increases seizure burden in extremely preterm neonates: a preliminary study. J Caffeine Res. 2016 Sep;6(3):101-7.

133 Halliday HL. Update on postnatal steroids. Neonatology. 2017;111(4):415-22.

134 Zeng L, Tian J, Song F, Li W, Jiang L, Gui G, et al. Corticosteroids for the prevention of bronchopulmonary dysplasia in preterm infants: a network meta-analysis. Arch Dis Child Fetal Neonatal Ed. 2018 Nov; 103(6):F506-11.

135 Doyle LW, Cheong JL, Ehrenkranz RA, Halliday HL. Early ([\{LT\}] 8 days) systemic postnatal corticosteroids for prevention of bronchopulmonary dysplasia in preterm infants. Cochrane Database Syst Rev. 2017 Oct;10:CD001146.

136 Yates HL, Newell SJ. Minidex: very low dose dexamethasone $(0.05 \mathrm{mg} / \mathrm{kg} /$ day $)$ in chronic lung disease. Arch Dis Child Fetal Neonatal Ed. 2011 May;96(3):F190-4.

137 Tanney K, Davis J, Halliday HL, Sweet DG. Extremely low-dose dexamethasone to facilitate extubation in mechanically ventilated preterm babies. Neonatology. 2011; 100(3):285-9.

138 Baud O, Maury L, Lebail F, Ramful D, El Moussawi F, Nicaise C, et al.; PREMILOC trial study group. Effect of early low-dose hydrocortisone on survival without bronchopulmonary dysplasia in extremely preterm infants (PREMILOC): a double-blind, placebo-controlled, multicentre, randomised trial. Lancet. 2016 Apr;387(10030): 1827-36. 
139 Baud O, Trousson C, Biran V, Leroy E, Mohamed D, Alberti C; PREMILOC Trial group. Two-year neurodevelopmental outcomes of extremely preterm infants treated with early hydrocortisone: treatment effect according to gestational age at birth. Arch Dis Child Fetal Neonatal Ed. 2019 Jan; 104(1):F30-5.

140 Shah VS, Ohlsson A, Halliday HL, Dunn M. Early administration of inhaled corticosteroids for preventing chronic lung disease in very low birth weight preterm neonates. Cochrane Database Syst Rev. 2017 Jan;1:CD001969.

141 Bassler D, Plavka R, Shinwell ES, Hallman M, Jarreau PH, Carnielli V, et al.; NEUROSIS Trial Group. Early inhaled budesonide for the prevention of bronchopulmonary dysplasia. N Engl J Med. 2015 Oct;373(16): 1497-506.

142 Bassler D, Shinwell ES, Hallman M, Jarreau $\mathrm{PH}$, Plavka R, Carnielli V, et al.; Neonatal European Study of Inhaled Steroids Trial Group. Long-term effects of inhaled budesonide for bronchopulmonary dysplasia. N Engl J Med. 2018 Jan;378(2):148-57.

143 Shinwell ES. Are inhaled steroids safe and effective for prevention or treatment of bronchopulmonary dysplasia? Acta Paediatr. 2018 Apr;107(4):554-6.

144 McPherson C, Inder T. Perinatal and neonatal use of sedation and analgesia. Semin Fetal Neonatal Med. 2017 Oct;22(5):31420.

145 Coviello C, Popple Martinez M, Drovandi L, Corsini I, Leonardi V, Lunardi C, et al. Painful procedures can affect post-natal growth and neurodevelopment in preterm infants. Acta Paediatr. 2018 May;107(5):784-90.

146 Fleishman R, Mossabeb R, Menkiti O, Young M, Bains V, Cooperberg D. Transition to routine premedication for nonemergent intubations in a level IV neonatal intensive care unit. Am J Perinatol. 2018 Mar; 35(4):336-44.

147 Durrmeyer X, Dahan S, Delorme P, Blary S, Dassieu G, Caeymaex L, et al. Assessment of atropine-sufentanil-atracurium anaesthesia for endotracheal intubation: an observational study in very premature infants. BMC Pediatr. 2014 May;14(1):120.

148 Chandrasekharan P, Nrusimha A, Rawat M, Lakshminrusimha S. Using paralytic as part of premedication for elective intubation of premature neonates may result in transient impairment of ventilation. Am J Perinatol. 2018 Sep;35(11):1127-30.

149 Bellù R, de Waal K, Zanini R. Opioids for neonates receiving mechanical ventilation: a systematic review and meta-analysis. Arch Dis Child Fetal Neonatal Ed. 2010 Jul; 95(4):F241-51.

$150 \mathrm{Ng}$ E, Taddio A, Ohlsson A. Intravenous midazolam infusion for sedation of infants in the neonatal intensive care unit. Cochrane Database Syst Rev. 2017 Jan; 1: CD002052.
151 Stevens B, Yamada J, Ohlsson A, Haliburton $S$, Shorkey A. Sucrose for analgesia in newborn infants undergoing painful procedures. Cochrane Database Syst Rev. 2016 Jul; 7:CD001069.

152 Bruschettini M, Romantsik O, Zappettini S, Ramenghi LA, Calevo MG. Transcutaneous carbon dioxide monitoring for the prevention of neonatal morbidity and mortality. Cochrane Database Syst Rev. 2016 Feb;2: CD011494.

153 Hyttel-Sorensen S, Greisen G, Als-Nielsen B, Gluud C. Cerebral near-infrared spectroscopy monitoring for prevention of brain injury in very preterm infants. Cochrane Database Syst Rev. 2017 Sep;9:CD011506.

154 Wilson E, Maier RF, Norman M, Misselwitz B, Howell EA, Zeitlin J, et al.; Effective Perinatal Intensive Care in Europe (EPICE) Research Group. Admission hypothermia in very preterm infants and neonatal mortality and morbidity. J Pediatr. 2016 Aug; 175:6167.e4.

155 Sinclair JC. Servo-control for maintaining abdominal skin temperature at $36 \mathrm{C}$ in low birth weight infants. Cochrane Database Syst Rev. 2002;1(1):CD001074

156 Boundy EO, Dastjerdi R, Spiegelman D, Fawzi WW, Missmer SA, Lieberman E, et al. Kangaroo mother care and neonatal outcomes: a meta-analysis. Pediatrics. 2016 Jan; 137(1):e20152238.

157 Charpak N, Tessier R, Ruiz JG, Hernandez JT, Uriza F, Villegas J, et al. Twenty-year follow-up of kangaroo mother care versus traditional care. Pediatrics. 2017 Jan;139(1): e20162063.

158 Cotten CM. Antibiotic stewardship: reassessment of guidelines for management of neonatal sepsis. Clin Perinatol. 2015 Mar; 42(1):195-206

159 www.nice.org.uk/guidance/cg149

160 McPherson C, Liviskie C, Zeller B, Nelson MP, Newland JG. Antimicrobial stewardship in neonates: challenges and opportunities. Neonatal Netw. 2018 Mar;37(2):11623.

161 Bell EF, Acarregui MJ. Restricted versus liberal water intake for preventing morbidity and mortality in preterm infants. Cochrane Database Syst Rev. 2014;12(12):CD000503.

162 Barrington KJ. Management during the first $72 \mathrm{~h}$ of age of the periviable infant: an evidence-based review. Semin Perinatol. 2014 Feb;38(1):17-24.

163 Osborn DA, Schindler T, Jones LJ, Sinn JK, Bolisetty S. Higher versus lower amino acid intake in parenteral nutrition for newborn infants. Cochrane Database Syst Rev. 2018 Mar;3:CD005949.

164 Kawai M. Reevaluation of protein intake for preterm infants. Am J Perinatol. 2018 Oct; 35(12):1138-41.
165 Mihatsch WA, Braegger C, Bronsky J, Cai W, Campoy C, Carnielli V, et al. ESPGHAN/ESPEN/ESPR/CSPEN guidelines on pediatric parenteral nutrition. Clin Nutr. 2018 Dec;37(6 6 Pt B):2303-5.

166 Morgan J, Bombell S, McGuire W. Early trophic feeding versus enteral fasting for very preterm or very low birth weight infants. Cochrane Database Syst Rev. 2013 Mar; 3(3):CD000504.

167 Oddie SJ, Young L, McGuire W. Slow advancement of enteral feed volumes to prevent necrotising enterocolitis in very low birth weight infants. Cochrane Database Syst Rev. 2017 Aug;8:CD001241.

168 Quigley M, Embleton ND, McGuire W. Formula versus donor breast milk for feeding preterm or low birth weight infants. Cochrane Database Syst Rev. 2018 Jun; 6:CD002971.

169 Dempsey EM. What should we do about low blood pressure in preterm infants? Neonatology. 2017;111(4):402-7.

170 Batton B, Li L, Newman NS, Das A, Watterberg KL, Yoder BA, et al.; Eunice Kennedy Shriver National Institute of Child Health and Human Development Neonatal Research Network. Evolving blood pressure dynamics for extremely preterm infants. J Perinatol. 2014 Apr;34(4):301-5.

171 Pereira SS, Sinha AK, Morris JK, Wertheim DF, Shah DK, Kempley ST. Blood pressure intervention levels in preterm infants: pilot randomised trial. Arch Dis Child Fetal Neonatal Ed. doi: 10.1136/archdischild2017-314159.

172 Singh Y, Roehr CC, Tissot C, Rogerson S, Gupta S, Bohlin K, et al.; European Special Interest Group "Neonatologist Performed Echocardiography" (NPE). Education, training, and accreditation of Neonatologist Performed Echocardiography in Europeframework for practice. Pediatr Res. 2018 Jul;84(S1 Suppl 1):13-7.

173 Finn D, Roehr CC, Ryan CA, Dempsey EM Optimising intravenous volume resuscitation of the newborn in the delivery room: practical considerations and gaps in knowledge. Neonatology. 2017;112(2):163-71.

174 Subhedar NV, Shaw NJ. Dopamine versus dobutamine for hypotensive preterm infants. Cochrane Database Syst Rev. 2003; 3(3):CD001242.

175 Durrmeyer X, Marchand-Martin L, Porcher R, Gascoin G, Roze JC, Storme L, et al.; Hemodynamic EPIPAGE 2 Study Group. Abstention or intervention for isolated hypotension in the first 3 days of life in extremely preterm infants: association with short-term outcomes in the EPIPAGE 2 cohort study. Arch Dis Child Fetal Neonatal Ed. 2017 Nov; 102(6):490-6.

176 Ibrahim H, Sinha IP, Subhedar NV. Corticosteroids for treating hypotension in preterm infants. Cochrane Database Syst Rev. 2011 Dec;12(12):CD003662. 
Peeples ES. An evaluation of hydrocortisone dosing for neonatal refractory hypotension. J Perinatol. 2017 Aug;37(8):943-6.

178 Ohlsson A, Walia R, Shah SS. Ibuprofen for the treatment of patent ductus arteriosus in preterm or low birth weight (or both) infants. Cochrane Database Syst Rev. 2018 Sep;9:CD003481.

179 Ohlsson A, Shah PS. Paracetamol (acetaminophen) for patent ductus arteriosus in preterm or low birth weight infants. Cochrane Database Syst Rev. 2018 Apr;4: CD010061.

180 Mitra S, Florez ID, Tamayo ME, Mbuagbaw L, Vanniyasingam T, Veroniki AA, et al. Association of placebo, indomethacin, ibuprofen, and acetaminophen with closure of hemodynamically significant patent ductus arteriosus in preterm infants: a systematic review and meta-analysis. JAMA. 2018 Mar; 319(12):1221-38

181 Schmidt B, Davis P, Moddemann D, Ohlsson A, Roberts RS, Saigal S, et al.; Trial of Indomethacin Prophylaxis in Preterms Investigators. Long-term effects of indomethacin prophylaxis in extremely-low-birthweight infants. N Engl J Med. 2001 Jun; 344(26): 1966-72.
182 Hundscheid T, Onland W, van Overmeire B, Dijk P, van Kaam AH, Dijkman KP, et al. Early treatment versus expectative management of patent ductus arteriosus in preterm infants: a multicentre, randomised, non-inferiority trial in Europe (BeNeDuctus trial). BMC Pediatr. 2018 Aug;18(1):262.

183 Weisz DE, Mirea L, Rosenberg E, Jang M, Ly L, Church PT, et al. Association of patent ductus arteriosus ligation with death or neurodevelopmental impairment among extremely preterm infants. JAMA Pediatr. 2017 May;171(5):443-9.

184 https://b-s-h.org.uk/guidelines/guidelines/ transfusion-for-fetuses-neonates-and-older-children/

185 Whyte RK, Kirpalani H, Asztalos EV, Andersen C, Blajchman M, Heddle N, et al.; PINTOS Study Group. Neurodevelopmental outcome of extremely low birth weight infants randomly assigned to restrictive or liberal hemoglobin thresholds for blood transfusion. Pediatrics. 2009 Jan;123(1): 207-13.

186 Howarth C, Banerjee J, Aladangady N. Red blood cell transfusion in preterm infants: current evidence and controversies. Neonatology. 2018;114(1):7-16.
187 Deshpande S, Suryawanshi P, Ahya K, Maheshwari R, Gupta S. Surfactant therapy for early onset pneumonia in late preterm and term neonates needing mechanical ventilation. J Clin Diagn Res. 2017 Aug;11(8): SC09-12.

188 Aziz A, Ohlsson A. Surfactant for pulmonary haemorrhage in neonates. Cochrane Database Syst Rev. 2012 Jul;7(7):CD005254.

189 El Shahed AI, Dargaville PA, Ohlsson A, Soll R. Surfactant for meconium aspiration syndrome in term and late preterm infants. Cochrane Database Syst Rev. 2014 Dec; 12(12):CD002054.

190 Barrington KJ, Finer N, Pennaforte T. Inhaled nitric oxide for respiratory failure in preterm infants. Cochrane Database Syst Rev. 2017 Jan;1:CD000509.

191 Ellsworth KR, Ellsworth MA, Weaver AL, Mara KC, Clark RH, Carey WA. Association of early inhaled nitric oxide with the survival of preterm neonates with pulmonary hypoplasia. JAMA Pediatr. 2018 Jul; 172(7):e180761.

192 Dixon F, Ziegler DS, Bajuk B, Wright I, Hilder L, Abdel Latif ME, et al. Treatment with nitric oxide in the neonatal intensive care unit is associated with increased risk of childhood cancer. Acta Paediatr. 2018 Dec; 107(12):2092-8. 